\title{
NRAGE, a potential biomarker, induces radioresistance in two- and three-dimensional culture and confers poor prognosis in esophageal squamous cell carcinoma
}

\author{
Huandi Zhou \\ 71213-Second Hospital of Hebei Medical University \\ Guohui Wang \\ 71213-Second Hospital of Hebei Medical University \\ Zhiqing Xiao \\ 71213-Second Hospital of Hebei Medical University \\ Yu Yang \\ 71213-Second Hospital of Hebei Medical University \\ Chen Gao \\ 71213-Second Hospital of Hebei Medical University \\ Xuetao Han \\ 71213-Second Hospital of Hebei Medical University \\ Wei Sun \\ 71213-Second Hospital of Hebei Medical University \\ Liubing Hou \\ 71213-Second Hospital of Hebei Medical University \\ Junling Liu \\ 71213-Second Hospital of Hebei Medical University \\ Xiaoying Xue ( $\sim$ xxy0636@163.com ) \\ Second Hospital of Hebei Medical University https://orcid.org/0000-0002-4934-2904
}

\section{Research}

Keywords: esophageal squamous cell carcinoma, Radioresistance, NRAGE, 3D bio-printing, Wnt/ $\beta$-catenin

Posted Date: November 18th, 2020

DOI: https://doi.org/10.21203/rs.3.rs-104545/v1

License: @) (1) This work is licensed under a Creative Commons Attribution 4.0 International License. Read Full License 


\section{Abstract Background}

To explore the mechanism of NRAGE enhancing radioresistance of ESCC in 2D and 3D levels.

\section{Methods}

Stably NRAGE-overexpressed ESCC cells and 3D-printing models for ESCC cells were established. Then, cellular malignancy indexes, such as cell morphology, proliferation, radioresistance, motility, apoptosis, cell cycle, and proteins of the Wnt/ $\beta$-catenin pathway, were compared between radioresistant and its parental cells in 2D and 3D levels. Additionally, 44 paraffin ESCC specimens with radical radiotherapy were selected to examine NRAGE and $\beta$-catenin protein expression and analyze the clinical correlation.

\section{Results}

Experiments in 2D culture showed that Eca109/NRAGE cells' morphology was more irregular, elongated spindle-shaped and disappeared polarity. It obtained faster growth ability, stronger resistance to irradiation, enhanced motility, reduced apoptosis ratio and cell cycle rearrangement. Moreover, Western blot results showed $\beta$-catenin, $p$-Gsk-3 $\beta$ and CyclinD1 expressions were induced, while $p$ - $\beta$-catenin and Gsk-3 $\beta$ expressions decreased in Eca109/NRAGE cells. Experiments in the 3D-printing model showed Eca109/NRAGE cell-laden 3D scaffolds had the advantage on growth and spheroiding according to the brigbtfield observation, scanning electron microscopy and $\mathrm{Ki}-67 \mathrm{IHC}$ staining, and higher expression at the $\beta$-catenin protein. Clinical analysis showed that NRAGE expression was higher in tumor tissues than in control tissues of ESCC patients from the Public DataBase. Compared with radiotherapy effective group, both NRAGE total and nuclear and $\beta$-catenin nuclear expressions were significantly upregulated from ESCC specimens in invalid group. Further analysis showed a positive and linear correlation between NRAGE nuclear and $\beta$-catenin nuclear expressions. Additionally, results from univariate and multivariate analyses revealed NRAGE nuclear expression could serve as a risk factor for ESCC patients receiving radical radiotherapy.

\section{Conclusion}

ESCC cells with NRAGE nuclear accumulation demonstrated greater radioresistance, which may be related to the activation of the Wnt/ $\beta$-catenin signaling pathway. It indicated that NRAGE nuclear expression was a potential biomarker for monitoring radiotherapeutic response.

\section{Background}

Esophageal cancer (EC), arising from esophageal epithelial cells, is an epidemic malignancy with conspicuous geographic distributions worldwide. It is fairly well known that China is one of the regions with a high incidence rate of ESCC, which has an enormous burden and is a major histological subtype accounting for $95 \%$ of ECs in China[1-3]. Statistically, the 5-year OS rate for ESCC is approximately 15-25\%. Even worse, patients will have poorer prognosis if diagnosed with locally advanced ESCC[4, 5]. Radiotherapy (RT) is one of the main treatment methods for ESCC, especially for inoperable and locally advanced ESCC, on which RT plays a crucial role. Although the prognosis of patients with ESCC receiving radical RT has dramatically improved recently, owing to better RT technology, the 5-year survival rate of ESCC treated with RT is suboptimal[6]. However, the response of ESCC to irradiation (IR) is limited so that numerous patients with ESCC cannot benefit from RT due to radioresistance, which is a major hurdle for successful treatment $[7,8]$. Undoubtedly, exploring molecular markers, which may regulate ESCC radioresistance, to improve clinical outcomes is of primary concern in increasing survival of patients with ESCC. 
NRAGE, a neurotrophin-receptor-interacting melanoma antigen-encoding gene homolog, also known as MAGED1 or DIxin-1, was discovered as a new member of the melanoma antigen family and encodes a cancer-related protein $[9,10]$. Given its diverse cellular functions, NRAGE is deemed to be greatly crucial in cancer development and progression. Current researchers reported that there were complex and apparently controversial functions on different tumors' progression, metastasis, and invasion[11, 12]. Initially, NRAGE was reported as a cancer suppressor gene, which promotes cell apoptosis via binding to P75NTR[13], Che1[14], XIAP-TAK1-TAB1[15], and UNC5H1[16] and inhibits proliferation[17] and angiogenesis[18]. Contradictorily, functions such as pro-apoptotic gene and growth promotion were slowly discovered [9, 11, 19-22]. Kodera et al. [21] found that increased NRAGE expression affects the malignant phenotype of HCC via its interaction with AATF. Zou et al.[20] proved that NRAGE may be a potential biomarker for HCC early diagnosis due to its ability of distinguishing HCC from benign liver disease. Yang et al. [22] reported that an aberrant NRAGE expression in both mRNA and protein levels in ESCC tissues was detected and could induce DNA-damaging chemoresistance by regulating homologous recombination repair.

Originally, our previous studies indicated that NRAGE was significantly overexpressed in the nucleus of ESCC cells with radioresistance[19] and knockdown NRAGE has significantly enhanced radiosensitivity in established radioresistant ESCC cells [11]. Scantily, there were only instantaneous intervention at constructed radioresistant EC cells cultured in the 2D level and no correlation with OS of ESCC. Surprisingly, the 3D culture system has a unique superiority in more similar tumor cell growth microenvironment than the $2 \mathrm{D}$ in vitro system and more short research cycles than the $2 \mathrm{D}$ in vivo system. This study aimed to confirm the tumor promotor function of NRAGE in ESCC and mechanism that it can accelerate cell growth and survival and induce radioresistance in 2D and 3D culture levels and confer poor prognosis in the clinical setting.

\section{Materials And Methods}

\section{Patient characteristics}

All 44 patients who were clinically and histopathologically diagnosed with primary ESCC based on the WHO criteria, were received radical RT through conventional fractionated RT by $6 \mathrm{MV}$ X-ray linear accelerator at the Second Hospital of Hebei Medical University from January 2010 to December 2015. The curative effects in the 44 patients were determined 1-3 months later after RT referring to the evaluation standard of esophageal barium swallow. The patients' tissue specimens were collected, fixed in $4 \%$ formalin, and embedded in paraffin. The patients' informed consent was obtained, and the study was approved by the Ethics Committee of the Second Hospital of Hebei Medical University (No.20160275). Patient baseline characteristics were shown in Table S2.

\section{3D bioprinting of $\mathrm{E}$ and $\mathrm{E} / \mathrm{N}$ cells}

Before printing, the 3D printed workstation (Regenovo Bio-Architect ${ }^{\circledR}$ WS, Hangzhou, China) was sterilized by $75 \%$ v/v ethanol and irradiated under UV for $30 \mathrm{~min}$. $\mathrm{E}$ and $\mathrm{E} / \mathrm{N}$ cells $\left(5 \times 10^{6}\right)$ were suspended in $0.2 \mathrm{~mL}$ culture medium, followed by addition of $3 \mathrm{~mL}$ of a gelatin-sodium alginate blend (10\% gelatin and $3 \%$ sodium alginate). Gelatin and sodium alginate were purchased from Sigma (St. Louis, MO, USA). The temperature of 3D-printed platform was set at $8^{\circ} \mathrm{C}$ with the size of $10 \times 10 \times 1.4 \mathrm{~mm}$. After printing, the hydrogels were soaked in $3 \%$ calcium chloride for 3 min for a crosslink reaction. Subsequently, the 3D bioprinted scaffolds were incubated at $37^{\circ} \mathrm{C}$ with $5 \% \mathrm{CO}_{2}$.

\section{Live/dead staining}

The survival rate of newly printed 3D structure $\mathrm{E}$ and $\mathrm{E} / \mathrm{N}$ cells was detected by fluorescent live/dead viability assay kit (KeyGen Biotech, Co., Ltd., Nanjing, China) according to the manufacturer's instructions. 3D cell-laden constructs were immersed in $1 \mathrm{~mL}$ PBS containing $8 \mu \mathrm{M} \mathrm{PI}$ (red, staining dead cells) and $2 \mu \mathrm{M}$ calcein AM (green, staining living cells) under the conditions of protection from light at room temperature reaction for $15 \mathrm{~min}$ and then washed with PBS. Stained cells were imaged using an inverted fluorescence phase contrast microscope (Zeiss, Germany). Live/dead cells were counted in five random fields at $100 \times$ magnification for each sample. The cell death rate was calculated as follows: ratio of cell survival=number of living cells/(number living cells+dead cells) $\times 100 \%$. 
$\mathrm{E}$ and $\mathrm{E} / \mathrm{N}$ cell proliferation in $3 \mathrm{D}$ bioprinted hydrogels were tested using an alamarBlue ${ }^{\mathrm{TM}}$ cell viability reagent (Invitrogen, USA). 3D-printed scaffolds were washed with PBS, and $500 \mu \mathrm{L}$ of alamarBlue working solution (alamarBlue: medium=1:9) was added to each well of a 24-well plate. Then, the 24-well plate was incubated at $37^{\circ} \mathrm{C}$ and $5 \% \mathrm{CO} 2$ for $2 \mathrm{~h}$. Then, each $100 \mu \mathrm{L}$ of working solution was transferred to a 96-well plate, and the absorbances at electron fixation solution at 570 and $600 \mathrm{~nm}$ on a multi-function microporous plate detector (bioTek Synergy H1, USA). The scaffolds were cultured for 19-21 days, and the OD values at 570 and $600 \mathrm{~nm}$ were detected every 2 days. The cell proliferation ratio calculation was as follows: reduction rate(\%) $=(A 570-A 600 \times R) \times 100 \% ; R=\left(A 570_{\text {control }} \mathrm{A}^{\prime} 570_{\text {control }}\right) /\left(A 600_{\text {control }} \mathrm{A}^{\prime} 600_{\text {control }}\right) ; A 570_{\text {control }}$ and $A 600_{\text {control, }}$, the OD values at 570 and $600 \mathrm{~nm}$ of cell-free alamarBlue working solution; $A^{\prime} 570_{\text {control }}$ and $A^{\prime} 600_{\text {control, }}$ the OD values at 570 and $600 \mathrm{~nm}$ of cellfree medium.

\section{SEM analysis}

The 3D-printed scaffolds at 7 and 14 days were fixed with 2.5\% glutaraldehyde (Solarbio, Beijing, China) for the night at room temperature and washed three times with PBS for $15 \mathrm{~min}$. The samples were soaked in a series of ethanol solutions (30\%, 50\%, $70 \%, 80 \%, 90 \%, 95 \%$, and $100 \%$ ) for $15 \mathrm{~min}$ in each solution for dehydration. Subsequently, the scaffolds were dried in the ventilated kitchen. Then, the constructs were coated with platinum ( $5 \mathrm{~nm}$ thickness) and imaged with an Ultra-55 SEM (Zeiss, Germany).

6. Cell culture, plasmids and stable transfection, realtime PCR, Western blot analysis, CCK-8 assay, IR and clonogenic assay, wound healing assay, transwell invasion assay, flow cytometry analysis, histology, and immunohistochemistry (IHC)

Experimental analyses were conducted as described previously[11],[23] and detailed in Supplementary materials and methods.

\section{Statistical analysis}

In vitro experiments were analyzed by unpaired two-sided Student's t-test, Welch's t-test, one-way analysis of variance (ANOVA) or two-way ANOVA. The total and nuclear protein expression of NRAGE and $\beta$-catenin in ESCC tissues were analyzed by MannWhitney U test. Survival curves were plotted using the Kaplan-Meier method and compared using the log-rank (Mantel-Cox) test. These statistical analyses were conducted by GraphPad Prism 8.0 software. Clinicopathological characteristics of patients with EC following radical RT were analyzed using the chi-squared test. The correlation between NRAGE or $\beta$-catenin and clinicopathological features of patients was analyzed using Spearman analysis. The linear correlation between NRAGE nuclear protein and $\beta$-catenin nuclear protein were analyzed using the Mantel-Haenszel chi-squared test. Survival data were evaluated using univariate log-rank test and multivariate Cox regression analyses. These data were analyzed using SPSS 25 statistical software (SPSS Inc., Chicago, IL, USA). A P-value $₫ 0.05$ was considered statistically significant.

\section{Results}

\section{Overexpression of NRAGE induces radioresistance of ESCC cells in 2D culture}

Our previous studies indicated that NRAGE was upregulated in ESCC radioresistant cells and extremely likely to be an RT-related critical factor $[11,19,24]$. Inadequately, there was lack of direct evidence to confirm the effect of NRAGE on resistancepromoting to IR. To verify the association between NRAGE and ESCC radioresistance, the expression of NRAGE in three types of ESCC cells, TE13, Kyse170, and Eca109, were compared (Fig 1a, b). Moreover, Eca109 cells with the least NRAGE expression was selected to stably overexpress NRAGE (Fig 1c, d). First, compared with Eca109-vector cells (indicated below as E), we aimed to identify the cellular changes resulting from expression of NRAGE in Eca109 cells (indicated below as E/N). It was visibly different in morphological distinction with more irregular, elongated spindle-shaped cells and disappearance of polarity (Fig 1e). Additionally, cell proliferation and radiosensitivity were tested through CCK-8 and clone formation assay. E/N cell exhibits its super growth ability and radiation-hardened effect (Fig 1f, g, h). Before exposure to IR, both E and E/N cells showed vigorous multiplication without difference during the first 4 days. From the fifth day, E/ $\mathrm{N}$ cells displayed enhanced proliferation 
ability. However, in the IR group, the significant difference between them was observed early at the fourth day (Fig 1f). Moreover, $\mathrm{E}$ and $\mathrm{E} / \mathrm{N}$ cells were exposed to different doses of radiation for colony formation. $\mathrm{E} / \mathrm{N}$ cells showed relatively higher colony survival rates and increased radiobiological parameter, $S F 2$ ( $E$ vs $E N=0.518$ vs 0.636$)$, D0 (E vs EN=1.443 vs 1.901), and Dq ( $E$ $v s \mathrm{EN}=1.338$ vs 1.603), under a series of doses of $0,2,4,6,8$, and $10 \mathrm{~Gy}$ (Table S1; Fig 1g, h). These results suggest that NRAGE overexpression induces radioresistance of ESCC cells in 2D culture.

2. Overexpression of NRAGE inhibits cell migration, invasion, cell cycle progression and apoptosis after IR in 2D culture

To further define the mechanism of NRAGE in ESCC radioresistance, cell migration, invasion, cell cycle progression, and apoptosis in $\mathrm{E} / \mathrm{N}$ cells were analyzed apart from the detection of proliferation. Wound healing assays were performed in $\mathrm{E}$ and $\mathrm{E} / \mathrm{N}$ cells with or without $5 \mathrm{~Gy}$ X-ray radiation and then imaged at $12 \mathrm{~h}$ and $24 \mathrm{~h}$. Results showed that ESCC cells with upregulated NRAGE had significantly faster migration ratio than E cells, especially after IR (Fig 2a, b). Transwell assays also showed that the number of invasion cells through the membrane regardless of the presence of IR was significantly larger in $E / N$ cells (Fig 2c, d). It revealed that NRAGE may enhance invasion and migration of ESCC cells after IR led to more resistive effect to IR. Cell apoptosis assays showed that the rate of spontaneous apoptosis in $\mathrm{E} / \mathrm{N}$ cells was significantly decreased (E vs $\mathrm{E} / \mathrm{N}$, $7.99 \% \pm 0.50 \%$ vs $4.16 \% \pm 0.15 \%, p=0.0057)$. After $\mathrm{RT}$, $\mathrm{E} / \mathrm{N}$ cells had lower apoptosis than $\mathrm{E}$ cells ( $\mathrm{E}$ vs $\mathrm{E} / \mathrm{N}, 24.29 \% \pm 1.12 \%$ vs $34.63 \% \pm 1.83 \%, p<0.0001$ ) (Fig 2e, f). Furthermore, we analyzed cell cycle progression of $E$ and $E / N$ cells with or without 5 Gy IR (Fig 2g, h). It was found that, before IR exposure, NRAGE overexpression was associated with an increased percentage of cells in the $S$ phase $(33.23 \pm 1.78$ vs $25.69 \pm 1.70, p=0.01)$, the most radioresistant cell stage, and a lower ratio in the most radiosensitive cell stage $\mathrm{G} 2 / \mathrm{M}(18.87 \pm 0.46$ vs $27.91 \pm 0.81, p=0.0018)$. After treatment with $5 \mathrm{~Gy} \mathrm{IR}$, cell cycle distributions were rearranged to a greater extent with more arrested cells in the S phase $(26.46 \pm 5.61$ vs $16.27 \pm 2.71, p=0.0005)$ and G0/G1 phase $(45.50 \pm 4.95$ vs $35.21 \pm 0.96, p=0.0004)$ and downregulated cells in the $\mathrm{G} 2 / \mathrm{M}$ phase $(28.04 \pm 0.67$ vs $48.52 \pm 1.77, p<0.0001)$. These revealed that NRAGE overexpression could reduce cell apoptosis and change cell cycle division of ESCC, affecting cellular radioresistance.

3. NRAGE overexpression activates canonical Wnt signaling pathway in ESCC cells with 2D culture

Previous studies indicated that NRAGE had a potential association with $\beta$-catenin in the formation of radioresistance in ESCC[11], so we detected protein expression in canonical Wnt signaling pathway, including $\beta$-catenin, phosphorylation of $\beta$ -

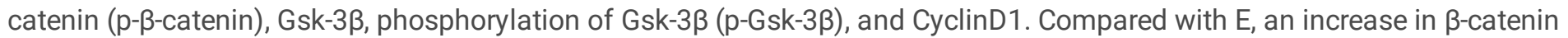
$(p=0.009)$ level, followed by increased $p-G s k-3 \beta$ levels $(p=0.002)$, led to the increased expression of cyclin D1 ( $p=0.032)$, a targeting gene of $\beta$-catenin in E/N cells, while downregulation of $p$ - $\beta$-catenin $(p<0.001)$ and Gsk-3 $\beta(p=0.016)$ was detected (Fig $3 a, b)$. These data indicated that, after NRAGE overexpression, the canonical Wnt signaling pathway was overall activated, which may be a switch-induced radioresistance.

\section{3D bioprinted ESCC cell-laden system cultured in vitro}

To the best of our knowledge, there is considerable difference on cancer cell morphology genetic profile and tumoral heterogeneity in 2D cultures. To focus more on the tumor cell growth environment and microenvironment in vitro, we selected culture cells in the 3D bioprinting system to identify the function of NRAGE in radioresistance of ESCC cells. A gelatin-alginate blend (10\% gelatin and $3 \%$ sodium alginate) was used as the $3 \mathrm{D}$ bioprinted material. Hydrogel seeded with $\mathrm{E}$ and $\mathrm{E} / \mathrm{N}$ cells were extruded at variable pressure ( $0.31 \mathrm{MPa})$, needle type (cylindrical), and needle diameter $(340 \mu \mathrm{m})$ to study cell characteristics directly after printing. Extruded gelatin-alginate blend was stained with live/dead dye and imaged (Fig 4a, b). Most cells remained viable (green), and only a small number of dead cells (red) were observed. Subsequently, the result of the analyses showed that dead or live cells were counted to quantify cell survival at $>80 \%$ and $\mathrm{E} / \mathrm{N}$ cell-laden $3 \mathrm{D}$-scaffolds exhibited stronger survivability. After printing, images were obtained, followed by crosslinking in $3 \% \mathrm{CaCl}_{2}$ and incubation at $37^{\circ} \mathrm{C}$ to allow the gelatin to leach out. The cell-laden 3D-scaffolds had a grid-like structure arranged in multiple layers, and cells were uniformly distributed in porous scaffolds with tight order, exhibiting good cytocompatibility (Fig 4c). At the first week, the printed scaffolds did not display obvious proliferation. Then, the cell growth rate accelerated slowly over time. After 3 weeks, cells began to grow into spheroids and pushed the surrounding hydrogels aside to occupy a larger space. Especially for E/ $\mathrm{N}$ cell-

Page 5/33 
laden hydrogels, the phenomena were highlighted. It was extremely biomimetic to the solid tumor growth in vivo. SEM observations revealed the spheroids bulged out over the scaffolds surface, and the trace of cells squeezed the surrounding hydrogel, which showed that E/N cell-laden scaffolds were apt to spheroiding. It was also suggested that E/N cells in the 3D group have a significantly higher secretion of growth hormone than E cells, and the difference gradually became pronounced over time (Fig 4e). After culture for 7 days, as shown in HE staining, individual cells scattered in printed scaffolds were observed (Fig 4f). During the culture period, natural gelatin began to degrade gradually via hydrolysis in the culture medium and then provided space for cells proliferating in clusters at 14 and 21 days. Furthermore, more and larger cell clusters were observed in E/N cell-laden 3D scaffolds. Fig. 4G showed the results of IHC staining for NRAGE that E/N cells in the 3D culture system had a distinct positive staining in nuclear cells with larger clusters. These results implied that cells with NRAGE overexpression in the 3D culture system are more suitable for survival and cloud growth, which hinted that ESCC cells with NRAGE overexpression exerted greater adaptability to survive and multiply.

\section{NRAGE overexpression enhanced the proliferation and radioresistance of ESCC cells in 3D bioprinted hydrogels}

The obvious advancement and characteristic of the 3D-printed model showed more similar growth environment and microenvironment in vivo. To identify the effect of NRAGE overexpression in ESCC cells cultured in the 3D-printed model on proliferation of tumor cells, alamarBlue assays were selected to compare cell viability between 3D-printed and 2D groups. As shown in Fig 5a, regardless of the culture condition (2D or 3D), E/ $\mathrm{N}$ cells had considerably higher survival percentages than $\mathrm{E}$ cells. More interestingly, there was a faster proliferation rate in E/ $\mathrm{N}$ cells in the 2D group in the first 20 days, whereas the 3Dprinted group showed a significantly higher proliferation rate of cells after 20 days. Similarly, an apparent trend that $E$ cells in the 3D-printed group would proliferate faster than those in the 2D group after 21 days was observed (Fig 5a). Moreover, the difference in responses to IR between $\mathrm{E}$ and $\mathrm{E} / \mathrm{N}$ cells in the 3D-printed model was identified by alamarBlue assays after $5 \mathrm{~Gy}$ IR. Evidently, E/N-3D cells had an absolute dominance of survival on resistance to IR compared with E-3D cells (Fig 5b). Deeply, the protein expression of Ki-67, a marker for cell proliferation activity, between E-3D and E/N-3D cells with or without 5 Gy IR, was evaluated by IHC, and both of them had a positive expression in relative individual cells scattered in hydrogel at 7 days. However, after 14 days, more positive staining in larger clusters in E/N-3D cells appeared. Furthermore, this different trend was also found after 5 Gy IR (Fig 5c). To verify whether the $\beta$-catenin expression change in ESCC cells with NRAGE overexpression was consistent from 2D to 3D groups, IHC staining was performed. Similarly, in the first 7 days, both E-3D and E/N-3D cells had a higher $\beta$-catenin expression levels with larger cell clusters. After culture for 14 days, larger E/N-3D cell clusters were stained positively by $\beta$-catenin antibody compared with those in $E$ cells. Unsurprisingly, there was a more obvious distinction between groups after $5 \mathrm{~Gy}$ IR. The results confirmed further that accelerated NRAGE expression in ESCC cells activate $\beta$-catenin expression to regulate radiosensitivity.

\section{NRAGE is upregulated in patient samples with EC following radical RT and correlated with poor prognosis}

We analyzed NRAGE expression in published profiles of patients with ESCC and found that it was upregulated in ESCC samples (182 cases) compared with adjacent normal tissue samples (286 cases) ( $p<0.05$, Fig 6a) (match TCGA normal and GTEx data, http://gepia.cancer-pku.cn/). Additionally, to thoroughly explore the role of NRAGE on radioresistance of ESCC and relationship with $\beta$-catenin, we further analyzed the expression of NRAGE and $\beta$-catenin in a total of 44 paraffin-embedded, ESCC tumor tissues receiving definitive RT (Table s2). As shown in Fig. 6A, the 1-, 3-, and 5-year overall survival rate of 44 patients were $69 \%$, $36 \%$, and $21 \%$, respectively (Fig $6 \mathrm{~b}$ ). According to the evaluation criteria of RT curative effect, 36 patients were classified in the efficacy group (complete response, CR, 26 patients, and partial response, PR, 9 patients) and 8 patients were classified in the inefficacy group (No response, NR, 8 cases) (Fig 6d-f). There were statistically significant differences between the two groups in the $1-3$-, and 5 -year OS rate: $81 \%, 45 \%$, and $26 \%$ for the efficacy group and only $15 \%$ of 1 -year OS rate in the inefficacy group were achieved ( $p=0.0001$ ) (Fig 6c). Compared to the inefficacy group in which NRAGE and $\beta$-catenin were expressed at low levels (Fig $6 \mathrm{~g}$ and $\mathrm{i}$ ), NRAGE and $\beta$-catenin were overexpressed, especially for positive nuclear expression, in efficacy group specimens (Fig. $6 \mathrm{H}$ and $\mathrm{J}$ ). According to the analysis of relationship between staining score and short-term effect of RT, NRAGE protein expression was dramatically upregulated in the RT efficacy group (CR + PR) tumor tissues compared with the NR group $(p=0.015)$ (Fig 6k). Unsurprisingly, more NRAGE nuclear protein expression was detected in efficacy group $(p=0.0021)($ Fig 6l). 
Additionally, there was higher $\beta$-catenin total protein expression in the efficacy group than in the NR group ( $p=0.081)(F i g$ m). However, the difference in $\beta$-catenin nuclear protein expression between the two groups was significant ( $p=0.0037)$ (Fig 6n).

Routinely, we analyzed the association between NRAGE total/nuclear protein or $\beta$-catenin total/nuclear protein expressions and clinicopathological features of 44 patients with ESCC by Spearman analysis. It was revealed that the expression of NRAGE total protein, especially for NRAGE nuclear protein, was strongly associated with curative efficacy $(p=0.0023, p=0.006)$. However, regardless of NRAGE total protein or NRAGE nuclear protein, there was no association with age $(p=0.656, p=0.277)$, gender $(p=0.734, p=0.277)$, clinical stage $(p=0.932, p=0.759)$, tumor size $(p=0.121, p=0.488)$, LNM $(p=0.153, p=0.148)$, synchronous chemotherapy $(p=0.906, p=0.862)$, and events $(p=0.135, p=0.528)$ (Table 1). As shown in Table 1, no correlation between $\beta$ catenin expression and age $(p=0.288, p=0.231)$, sex $(p=1.000, p=0.0 .358)$, clinical stage $(p=0.824, p=0.986)$, tumor size $(p=0.168, p=0.263), \operatorname{LNM}(p=0.221, p=0.587)$, synchronous chemotherapy $(p=0.099, p=0.459)$, and events $(p=0.754, p=0.296)$ was found. A significant correlation could not be found between $\beta$-catenin total protein expression and clinicopathological features $(p=0.143)$, but a strong association between $\beta$-catenin nuclear protein expression and curative efficacy was observed $(p=0.006)$. Kaplan-Meier survival curves exhibited no association between OS in definitive RT and NRAGE or $\beta$-catenin total protein expression (Fig 60 and $q, p=0.198, p=0.504$ ), but a strong positive NRAGE nuclear protein expression was significantly shorter than those with positive and weak positive NRAGE expression (Fig $6 p, p<0.0001$ ). Additionally, there was a correlated trend between $\beta$-catenin nuclear protein expression and OS (Fig $6 r, p=0.081$ ). Moreover, we analyzed the association between NRAGE and $\beta$-catenin nuclear protein expressions and confirmed their linear correlation $\left(\chi^{2}=4.106, p=0.043\right)$ (Table s3). These results indicate that NRAGE expression, especially NRAGE nuclear expression, in patients with ESCC receiving radical RT was correlated with poor survival and may be linked to heightened $\beta$-catenin nuclear accumulation. Furthermore, univariate and multivariate analyses were used to determine whether NRAGE could be a risk factor in patients with ESCC receiving radical RT. Log-rank test in the univariate analysis showed that synchronous chemotherapy $(p=0.037)$, curative efficacy $(p=0.000)$, and strong positive NRAGE nuclear protein expression $(p=0.000)$ were associated with a significantly increased risk of death in patients with ESCC receiving radical RT (Table 2). Multivariate Cox regression analysis revealed that NRAGE nuclear protein could be a factor for predicting poor survival when it has strong positive expression $(R R=14.536, p=0.000)$. Synchronously, clinical stage $(R R=2.995, p=0.024)$ and synchronous chemotherapy $(R R=0.354, p=0.019)$ were included as factors (Table 2$)$. Collectively, all these indicated that NRAGE overexpression occurred during nuclear translocation after IR and stimulated $\beta$ catenin expression in the cytoplasm to increase the nuclear localization of $\beta$-catenin, which activated the Wnt/ $\beta$-catenin signaling pathway and then induced the radioresistance in ESCC. A flowchart of the possible mechanism is shown in Fig $6 \mathrm{~s}$.

\section{Discussion}

EC is one of the most common primary malignancy with high mortality, and mainly in ESCC in China. RT is one of the primary therapeutic modalities in patients with ESCC. The existence of radioresistance is a major limit to achieve long-term survival in ESCC, which has been linked to an increased likelihood of recurrence and distant metastasis[25-27].

NRAGE has complicated and contradictory functions. It encodes an $86-\mathrm{KD}$ a protein and is a member of the Type II MAGE family, comprising 778 amino acids (aa), of which the MAGE homology domain is common for MAGE family members and the interspersed repeat domain (IRD) is relatively unique to NRAGE for no homology to any public specific protein. These features imply that there are both uniform and specific characteristics of NRAGE compared with other members of the MAGE family[2830]. Growing evidence confirmed that NRAGE functions as a transcriptional regulator mediating multiple signaling pathways from proptosis[13-16], cell differentiation[31-33], cell cycle distribution[22], cell adhesion[34], and angiogenesis[18]. In contrast, NRAGE could promote cell apoptosis through interaction with P75NTR[13], Che-1[14], XIAP-TAK1-TAB1[15], and UNC5H1[16]. However, Kumar et al.[35] initially found the anti-apoptosis role of NRAGE, in which NRAGE had carried out anoikis resistance after it transferred into the nucleus and coacted with TBX2. Moreover, NRAGE also exerted cell differentiation functions through activating the transcriptional function of DIx5[31], downregulating TrkA[32], and been reducing by Praja1[33]. Furthermore, as an important adaptor, NRAGE could interact with PCNA to promote anti-apoptosis, accelerate cell growth, and change cell cycle distribution[22]. Additionally, NRAGE could regulate cell adhesion by participating in epithelial-mesenchymal transformation (EMT) activity[34] and angiogenesis by interfering with HIF-1-dependent gene expression[18]. Mitsuro et al.[30]

Page $7 / 33$ 
reported NRAGE's carcinogenic role that knockdown of NRAGE could reduce proliferation, migration, and invasion in gastric cancer cells, which was positively correlated with AATF. Generally, above mentioned studies indicate that NRAGE, as a molecular bridge, exerts complex and contradictory functions as either an inhibitor or promoter depending on different cell types.

Innovatively, our team provided a new insight for NRAGE into the ability of pro-radioresistance that NRAGE was unexpectedly overexpressed in radioresistant ESCC cells based on gene microarray analysis and experiment verification. It was shown that NRAGE had a growing trend following enhanced IR dose and time[19]. Another study of our team determined whether NRAGE subcellular localization alteration led to radioresistance and may be related to occurrence of EMT in ESCC[34]. Subsequently, our study verified that NRAGE was upregulated in constructed radioresistant cells from ESCC cells TE13 and Eca109 and participated in the information of radioresistance in ESCC[11]. Clinical sample detection revealed that there was high expression of NRAGE in patients with ESCC in the invalid group based on short-term efficacy evaluation treated with definitive RT. Inadequately, the abovementioned contents were obtained in 2D level, and the interference measure for NRAGE was transitory RNA interference (RNAi). In addition, the relationship between NRAGE expression and patients' OS was not analyzed. The evidence that NRAGE overexpression was related to poor prognosis of patients with ESCC treated by radical RT was relatively weak.

In this study, we selected Eca109 cells to artificially stably overexpress NRAGE, in which NRAGE expression was at a related lower level compared with those in TE13 and Kyse170 cells (Fig. 1a-d). After interference, accelerated growth speed, degressive apoptosis rate, more malignant migration and invasion, and redistributed cell cycle lead to accumulation of IR resistance in Eca109 cells with NRAGE overexpression (Fig. 1f-h, Fig. 2a-h). Moreover, the experiments in the cell level on the mechanism of NRAGE involved in radioresistance in ESCC cells were performed at both 2D and 3D levels. It is a truism that 3D printing technology has high precision and fast building speed, which can not only improve and more fully simulate the natural microenvironment in vivo but also shorten the research cycle compared with the mouse model[36-39]. In the 3D system, we printed the 3D E-cells and $\mathrm{E} / \mathrm{N}$ cell models using a gelatin-alginate blend (10\% gelatin and $3 \%$ sodium alginate). Through observing model morphology by brigbtfield and SEM, the 3D E/N cell model showed more powerful spheroiding capacity (Fig. 4d and e). From the results of HE staining, alamarBlue detection, and ki-67 IHC staining, more strong proliferation ability and resistance to IR were apparent (Fig. 4f, Fig. 5a-C). As for the mechanism of NRAGE participating in the information of radioresistance in ESCC cells, the Western blot analysis results on the total and phosphorylated $\beta$-catenin protein and total and phosphorylated Gsk-3 $\beta$ protein and $\beta$-catenin IHC stain results of 3D-cells scaffolds demonstrated that NRAGE may trigger $\beta$ catenin nuclear protein accumulation and then activate the canonical Wnt signaling pathways to motivate cancer-promoting activities (Fig. 3a, b).

$\beta$-catenin, a core member of the canonical Wnt signaling pathway, was strongly linked to EC progression, metastasis, and invasion[40-43]. In off state of canonical Wnt signaling pathways, $\beta$-catenin is mainly expressed at the cytoplasm, and Gsk-3 $\beta$

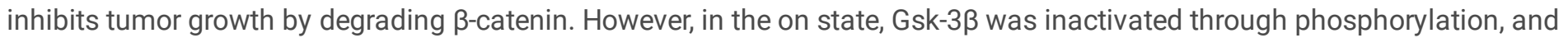
then $\beta$-catenin is accumulated in the cytoplasm so as to increase the nuclear localization of $\beta$-catenin, activating downstream target genes and modulating the behavior of tumor cells. Prominently, numerous investigations showed a close-knit relationship between radioresistance and $\beta$-catenin in $\mathrm{EC}[11,44-50]$. Che et al.[47] used fractionate IR to acquire radioresistant EC cells Eca109R50Gy and tested the aberrant expression of $\beta$-catenin. When treated with a COX-2 inhibitor, downregulation of $\beta$-caternin and enhanced radiosensitivity were observed. In 2014, Su et al. screened three mircroRNAs (mir-301a, mir-131, and mir-18b) based on human miRNA microarray results reserved on Public DataBase on radioresistant ESCC cell line KYSE-150R and its parental KYSE-150 and subsequent real-time qPCR verification. Target gene prediction revealed that wnt1 was a potential target gene of mir-301a and overexpressed in KYSE-150R[48]. Their subsequent study confirmed that microRNA-301a could increase the radiosensitivity and restrain the migration of ESCC cells with radioresistance through affecting canonical Wnt signaling pathways[44]. Another study of the team showed EMT phenotypes and acquisition of radioresistance in EC cells were related to activation of the canonical Wnt signaling pathway. Moreover, a type of this pathway inhibitor, FH535, can reverse the abovementioned phenomenon[45]. Previously, our team presented the correlation between NRAGE and $\beta$-catenin only in the cell level [11]. Unfortunately, many studies were short of clinical relevance. 
Profoundly, in the present study, with further analysis, we found the close-knit pertinence between NRAGE and $\beta$-catenin in the clinical setting, in which NRAGE protein expression level, especially for NRAGE nuclear protein, was negatively correlated to short-term efficacy and long-term survival of patients with ESCC receivingh radical RT (Tables 1 and 2). Meanwhile, a strong positive correlation between NRAGE and $\beta$-catenin nuclear expression were also observed using the chi-square linear trend test (Table s3). Comprehensively, the current results confirmed that IR may cause the upregulation of NRAGE, which could accumulate NRAGE to promote nuclear translocation, and triggered $\beta$-catenin nuclear accumulation to induce ESCC cells' proliferation and anti-proptosis, enhance invasiveness and migration capability and cell cycle rearrangement, and promote decreased radiosensitivity (Fig. 6s).

Collectively, our study verified the NRAGE, with anti-oncogene and oncogene contradictory roles, was regarded as an oncogene due to the functions that accelerated proliferation, anti-apoptosis effect, more malignant migration and invasion, and accumulation of IR resistance by triggering Wnt/ $\beta$-catenin signaling pathway in ESCC cells in 2D and 3D levels. Not only that, clinical correlation analysis also demonstrated that NRAGE, specifically for NRAGE nuclear protein, was a risk factor in patients with ESCC treated by definitive RT and had a positive relationship with $\beta$-catenin nuclear protein expression. As a putative oncogene, NRAGE may have the potential to serve as a novel predictive biomarker for tumor progression and target of molecular therapy.

\section{Abbreviations}

NRAGE= neurotrophin-receptor-interactingmelanoma antigen-encodinggenehomolog

ESCC $=$ esophageal squamous cell carcinoma

$2 \mathrm{D}=$ two-dimensional

$3 \mathrm{D}=$ three-dimensional

P75NTR =p75 neurotrophin receptor

AATF =apoptosis antagonizing transcription factor

OS=overall survival

HCC=hepatocellular carcinoma

SEM= Scanning electron microscopy

TCGA=The Cancer Genome Atlas

\section{Declarations}

\section{Ethics approval and consent to participate}

The study was approved by the Ethics Committee of the Second Hospital of Hebei Medical University (No.20160275).

\section{Consent for publication}

The patients' informed consent was obtained.

\section{Availability of data and material}

The data and materials supporting the conclusions are included within the article and its supplementary information files. 
Authors declare no conflicts of interest for this article.

\section{Funding}

This work is supported by Grants from Natural Science Foundation of Hebei Province (No. H2019206182).

\section{Authors' contributions}

$\mathrm{HZ}$ and GW, study design, data analysis, and manuscript writing. ZX, established cell lines, Tissue collection and Evaluation of radiotherapy efficacy. ZX, YY and ZT helped interpreted the data. CG, XH, SW and LH prepared all figures. ZZ, JL, HZ and GW edited all tables. $\mathrm{XY}$, experiment conduction.

\section{Acknowledgments}

This work is supported by Grants from Natural Science Foundation of Hebei Province (No. H2019206182).

\section{References}

1. Q. He, J. Li, F. Dong, C. Cai, X. Zou, LKB1 promotes radioresistance in esophageal cancer cells exposed to radiation, by suppression of apoptosis and activation of autophagy via the AMPK pathway. Mol Med Rep 16, 2205-2210 (2017)

2. Z. Strizova, M. Snajdauf, D. Stakheev, P. Taborska, J. Vachtenheim Jr, J. Biskup, R. Lischke, J. Bartunkova, D. Smrz, The paratumoral immune cell signature reveals the potential for the implementation of immunotherapy in esophageal carcinoma patients. J. Cancer Res. Clin. Oncol. (2020)

3. W. Zhou, J. Wu, X. Liu, M. Ni, Z. Meng, S. Liu, S. Jia, J. Zhang, S. Guo, X. Zhang, Identification of crucial genes correlated with esophageal cancer by integrated high-throughput data analysis. Medicine (Baltimore) 99, e20340 (2020)

4. A. Pennathur, M.K. Gibson, B.A. Jobe, J.D. Luketich, Oesophageal carcinoma. Lancet 381, 400-412 (2013)

5. R. Mallet, R. Modzelewski, J. Lequesne, S. Mihailescu, P. Decazes, H. Auvray, A. Benyoucef, F. Di Fiore, P. Vera, B. Dubray, S. Thureau, Prognostic value of sarcopenia in patients treated by Radiochemotherapy for locally advanced oesophageal cancer. Radiat Oncol 15, 116 (2020)

6. Z. Wang, J. Zhang, M. Li, L. Kong, J. Yu, The expression of p-p62 and nuclear Nrf2 in esophageal squamous cell carcinoma and association with radioresistance. Thorac Cancer 11, 130-139 (2020)

7. L. Yang, X. Zhang, Q. Hou, M. Huang, H. Zhang, Z. Jiang, J. Yue, S. Wu, Single-cell RNA-seq of esophageal squamous cell carcinoma cell line with fractionated irradiation reveals radioresistant gene expression patterns. BMC Genomics 20, 611 (2019)

8. H. Chen, X. Yao, X. Di, Y. Zhang, H. Zhu, S. Liu, T. Chen, D. Yu, X. Sun, MiR-450a-5p inhibits autophagy and enhances radiosensitivity by targeting dual-specificity phosphatase 10 in esophageal squamous cell carcinoma. Cancer Lett. 483, 114-126 (2020)

9. Q. Yang, Q. Pan, C. Li, Y. Xu, C. Wen, F. Sun, NRAGE is involved in homologous recombination repair to resist the DNAdamaging chemotherapy and composes a ternary complex with RNF8-BARD1 to promote cell survival in squamous esophageal tumorigenesis. Cell Death Differ. 23, 1406-1416 (2016)

10. L. Liu, Z. Cui, J. Zhang, J. Wang, S. Gu, J. Ma, H. Chen, L. Hang, J. Yang, Y. Shi, Knockdown of NRAGE Impairs Homologous Recombination Repair and Sensitizes Hepatoblastoma Cells to lonizing Radiation. Cancer Biother. Radiopharm. 35, 41-49 (2020)

11. H. Zhou, G. Zhang, X. Xue, Y. Yang, Y. Yang, X. Chang, X. Ge, Z. Xiao, H. Guo, Y. Wang, Identification of novel NRAGE involved in the radioresistance of esophageal cancer cells. Tumour Biol. 37, 8741-8752 (2016)

12. G. Zhang, H. Zhou, X. Xue, Complex roles of NRAGE on tumor. Tumour Biol. 37, 11535-11540 (2016)

13. A.H. Salehi, P.P. Roux, C.J. Kubu, C. Zeindler, A. Bhakar, L.L. Tannis, J.M. Verdi, P.A. Barker, NRAGE, a novel MAGE protein, interacts with the p75 neurotrophin receptor and facilitates nerve growth factor-dependent apoptosis. Neuron 27, 279-288 (2000) 
14. M.G. Di Certo, N. Corbi, T. Bruno, S. lezzi, F. De Nicola, A. Desantis, M.T. Ciotti, E. Mattei, A. Floridi, M. Fanciulli, C. Passananti, NRAGE associates with the anti-apoptotic factor Che-1 and regulates its degradation to induce cell death. J. Cell. Sci. 120, 1852-1858 (2007)

15. J.A. Rochira, N.N. Matluk, T.L. Adams, A.A. Karaczyn, L. Oxburgh, S.T. Hess, J.M. Verdi, A small peptide modeled after the NRAGE repeat domain inhibits XIAP-TAB1-TAK1 signaling for NF-KB activation and apoptosis in P19 cells. PLoS ONE 6, e20659 (2011)

16. M.E. Williams, P. Strickland, K. Watanabe, L. Hinck, UNC5H1 induces apoptosis via its juxtamembrane region through an interaction with NRAGE. J. Biol. Chem. 278, 17483-17490 (2003)

17. Q. Du, Y. Zhang, X.X. Tian, Y. Li, W.G. Fang, MAGE-D1 inhibits proliferation, migration and invasion of human breast cancer cells. Oncol. Rep. 22, 659-665 (2009)

18. W.G. Shen, Q.Y. Xue, J. Zhu, B.S. Hu, Y. Zhang, Y.D. Wu, Q. Su, Inhibition of adenovirus-mediated human MAGE-D1 on angiogenesis in vitro and in vivo. Mol. Cell. Biochem. 300, 89-99 (2007)

19. X.Y. Xue, Z.H. Liu, F.M. Jing, Y.G. Li, H.Z. Liu, X.S. Gao, Relationship between NRAGE and the radioresistance of esophageal carcinoma cell line TE13R120. Chin J Cancer 29, 900-906 (2010)

20. W. Zou, J. Cui, Z. Ren, Y. Leng, NRAGE is a potential diagnostic biomarker of hepatocellular carcinoma. Medicine (Baltimore) 97, e13411 (2018)

21. D. Shimizu, M. Kanda, H. Sugimoto, S. Sueoka, H. Takami, K. Ezaka, Y. Tanaka, R. Hashimoto, Y. Okamura, N. Iwata, C. Tanaka, S. Yamada, T. Fujii, G. Nakayama, M. Koike, S. Nomoto, M. Fujiwara, Y. Kodera, NRAGE promotes the malignant phenotype of hepatocellular carcinoma. Oncol Lett 11, 1847-1854 (2016)

22. Q. Yang, C. Ou, M. Liu, W. Xiao, C. Wen, F. Sun, NRAGE promotes cell proliferation by stabilizing PCNA in a ubiquitinproteasome pathway in esophageal carcinomas. Carcinogenesis 35, 1643-1651 (2014)

23. R. Miao, H. Luo, H. Zhou, G. Li, D. Bu, X. Yang, X. Zhao, H. Zhang, S. Liu, Y. Zhong, Z. Zou, Y. Zhao, K. Yu, L. He, X. Sang, S. Zhong, J. Huang, Y. Wu, R.A. Miksad, S.C. Robson, C. Jiang, Y. Zhao, H. Zhao, Identification of prognostic biomarkers in hepatitis B virus-related hepatocellular carcinoma and stratification by integrative multi-omics analysis. J. Hepatol. 61, 840849 (2014)

24. Z. Ping, Z.G. Zhou, X.S. Gao, Isolation and characterization of radioresistant human esophageal cancer cells and the differential gene expression by cDNA microarray analysis. Chinese Journal of Radiological Medicine \& Protection (2006)

25. A. Malhotra, U. Sharma, S. Puhan, N. Chandra Bandari, A. Kharb, P.P. Arifa, L. Thakur, H. Prakash, K.M. Vasquez, A. Jain, Stabilization of miRNAs in esophageal cancer contributes to radioresistance and limits efficacy of therapy. Biochimie 156, 148-157 (2019)

26. J. Liu, N. Xue, Y. Guo, K. Niu, L. Gao, S. Zhang, H. Gu, X. Wang, D. Zhao, R. Fan, CircRNA_100367 regulated the radiation sensitivity of esophageal squamous cell carcinomas through miR-217/Wnt3 pathway. Aging (Albany NY) 11, 12412-12427 (2019)

27. M. Li, L. Fan, D. Han, Z. Yu, J. Ma, Y. Liu, P. Li, D. Zhao, J. Chai, L. Jiang, S. Li, J. Xiao, Q. Duan, J. Ye, M. Shi, Y. Nie, K.C. Wu, D.J. Liao, Y. Shi, Y. Wang, Q. Yan, S. Guo, X.W. Bian, F. Zhu, J. Zhang, Z. Wang, Ribosomal S6 protein kinase 4 promotes radioresistance in esophageal squamous cell carcinoma. J. Clin. Invest. (2020)

28. Y. Zhou, N. Huang, J. Wu, N. Zhen, N. Li, Y. Li, Y.X. Li, Silencing of NRAGE induces autophagy via AMPK/Ulk1/Atg13 signaling pathway in NSCLC cells. Tumour Biol. 39, 1010428317709676 (2017)

29. X. Jiang, X. Jiang, Z. Yang, NRAGE confers poor prognosis and promotes proliferation, invasion, and chemoresistance in gastric cancer. Gene 668, 114-120 (2018)

30. M. Kanda, D. Shimizu, T. Fujii, H. Tanaka, Y. Tanaka, K. Ezaka, M. Shibata, H. Takami, R. Hashimoto, S. Sueoka, N. Iwata, D. Kobayashi, C. Tanaka, S. Yamada, G. Nakayama, H. Sugimoto, M. Koike, M. Fujiwara, Y. Kodera, Neurotrophin ReceptorInteracting Melanoma Antigen-Encoding Gene Homolog is Associated with Malignant Phenotype of Gastric Cancer. Ann. Surg. Oncol. 23, 532-539 (2016)

31. Y. Masuda, A. Sasaki, H. Shibuya, N. Ueno, K. Ikeda, K. Watanabe, Dlxin-1, a novel protein that binds Dlx5 and regulates its transcriptional function. J. Biol. Chem. 276, 5331-5338 (2001)

Page 11/33 
32. Z. Feng, K. Li, M. Liu, C. Wen, NRAGE is a negative regulator of nerve growth factor-stimulated neurite outgrowth in PC12 cells mediated through TrkA-ERK signaling. J. Neurosci. Res. 88, 1822-1828 (2010)

33. J. Teuber, B. Mueller, R. Fukabori, D. Lang, A. Albrecht, O. Stork, The ubiquitin ligase Praja1 reduces NRAGE expression and inhibits neuronal differentiation of PC12 cells. PLoS ONE 8, e63067 (2013)

34. X. Chang, X. Xue, Y. Zhang, G. Zhang, H. Zhou, Y. Yang, Y. Ran, Z. Xiao, X. Ge, H. Liu, The role of NRAGE subcellular location and epithelial-mesenchymal transition on radiation resistance of esophageal carcinoma cell. J Cancer Res Ther 14, 46-51 (2018)

35. S. Kumar, S.H. Park, B. Cieply, J. Schupp, E. Killiam, F. Zhang, D.L. Rimm, S.M. Frisch, A pathway for the control of anoikis sensitivity by E-cadherin and epithelial-to-mesenchymal transition. Mol. Cell. Biol. 31, 4036-4051 (2011)

36. A. Shafiee, 3D Printed Scaffolds for Cancer Precision Medicine. Tissue Eng Part A (2020)

37. Z. Fazili, A. Ward, K. Walton, L. Blunt, K. Asare-Addo, Design and development of a novel fused filament fabrication (FFF) 3D printed diffusion cell with UV imaging capabilities to characterise permeation in pharmaceutical formulations. Eur $\mathrm{J}$ Pharm Biopharm (2020)

38. C.L. Gordy, C.I. Sandefur, T. Lacara, F.R. Harris, M.V. Ramirez, Building the lac Operon: A Guided-Inquiry Activity Using 3DPrinted Models. J Microbiol Biol Educ 21, (2020)

39. G. Bahcecioglu, G. Basara, B.W. Ellis, X. Ren, P. Zorlutuna, Breast cancer models: Engineering the tumor microenvironment. Acta Biomater 106, 1-21 (2020)

40. F. Deng, K. Zhou, W. Cui, D. Liu, Y. Ma, Clinicopathological significance of wnt/ $\beta$-catenin signaling pathway in esophageal squamous cell carcinoma. Int J Clin Exp Pathol 8, 3045-3053 (2015)

41. J.A. Wall, S.J. Klempner, R.C. Arend, The anti-DKK1 antibody DKN-01 as an immunomodulatory combination partner for the treatment of cancer. Expert Opin Investig Drugs 1-6 (2020)

42. W. Wang, S. He, R. Zhang, J. Peng, D. Guo, J. Zhang, B. Xiang, L. Li, ALDH1A1 maintains the cancer stem-like cells properties of esophageal squamous cell carcinoma by activating the AKT signal pathway and interacting with $\beta$-catenin. Biomed. Pharmacother. 125, 109940 (2020)

43. X. Pan, L. Ma, J. Wang, The clinicopathological significance and prognostic value of $\beta$-catenin Ser45-phosphorylation expression in esophageal squamous cell carcinoma. Int J Clin Exp Pathol 12, 3507-3513 (2019)

44. H. Su, Y. Wu, Y. Fang, L. Shen, Z. Fei, C. Xie, M. Chen, MicroRNA-301a targets WNT1 to suppress cell proliferation and migration and enhance radiosensitivity in esophageal cancer cells. Oncol. Rep. 41, 599-607 (2019)

45. H. Su, X. Jin, X. Zhang, L. Zhao, B. Lin, L. Li, Z. Fei, L. Shen, Y. Fang, H. Pan, C. Xie, FH535 increases the radiosensitivity and reverses epithelial-to-mesenchymal transition of radioresistant esophageal cancer cell line KYSE-150R. J TransI Med 13, 104 (2015)

46. W.F. Li, L. Zhang, H.Y. Li, S.S. Zheng, L. Zhao, WISP-1 contributes to fractionated irradiation-induced radioresistance in esophageal carcinoma cell lines and mice. PLoS ONE 9, e94751 (2014)

47. S.M. Che, X.Z. Zhang, X.L. Liu, X. Chen, L. Hou, The radiosensitization effect of NS398 on esophageal cancer stem cell-like radioresistant cells. Dis. Esophagus 24, 265-273 (2011)

48. H. Su, X. Jin, X. Zhang, S. Xue, X. Deng, L. Shen, Y. Fang, C. Xie, Identification of microRNAs involved in the radioresistance of esophageal cancer cells. Cell Biol. Int. 38, 318-325 (2014)

49. H.Z. Li, X.S. Gao, W. Xiong, J. Zhao, H. Zhang, D.M. Zhou, Identification of differentially expressed genes related to radioresistance of human esophageal cancer cells. Chin J Cancer 29, 882-888 (2010)

50. X. Zhang, R. Komaki, L. Wang, B. Fang, J.Y. Chang, Treatment of radioresistant stem-like esophageal cancer cells by an apoptotic gene-armed, telomerase-specific oncolytic adenovirus. Clin. Cancer Res. 14, 2813-2823 (2008)

\section{Tables}

Table 1 spearman analysis of correlation among NRAGE, $\beta$-catenin and clinicopathological features

Page $12 / 33$ 


\begin{tabular}{|c|c|c|c|c|c|c|c|c|c|}
\hline \multirow[t]{2}{*}{ Variables } & \multirow[t]{2}{*}{ Group } & \multicolumn{2}{|c|}{ NRAGE expression } & \multicolumn{2}{|c|}{$\begin{array}{l}\text { NRAGE nuclear } \\
\text { expression }\end{array}$} & \multicolumn{2}{|l|}{$\begin{array}{l}\beta \text {-catenin } \\
\text { expression }\end{array}$} & \multicolumn{2}{|c|}{$\begin{array}{l}\text { B-catenin nuclear } \\
\text { expression }\end{array}$} \\
\hline & & $\begin{array}{l}\text { spearman } \\
\text { correlation }\end{array}$ & $\begin{array}{l}P \\
\text { value }\end{array}$ & $\begin{array}{l}\text { spearman } \\
\text { correlation }\end{array}$ & $\begin{array}{l}P \\
\text { value }\end{array}$ & $\begin{array}{l}\text { spearman } \\
\text { correlation }\end{array}$ & $\begin{array}{l}P \\
\text { value }\end{array}$ & $\begin{array}{l}\text { spearman } \\
\text { correlation }\end{array}$ & $\begin{array}{l}P \\
\text { value }\end{array}$ \\
\hline \multirow[t]{2}{*}{ Age(y) } & $\geq 60$ & -0.069 & 0.656 & -0.168 & 0.277 & -0.164 & 0.288 & 0.184 & 0.231 \\
\hline & $<60$ & & & & & & & & \\
\hline \multirow[t]{2}{*}{ Gender } & Male & 0.053 & 0.734 & 0.168 & 0.277 & 0.000 & 1.000 & 0.142 & 0.358 \\
\hline & Female & & & & & & & & \\
\hline \multirow[t]{2}{*}{ clinical stage } & $\mathrm{I}-\mathrm{II}$ & -0.013 & 0.932 & 0.048 & 0.759 & -0.034 & 0.824 & -0.003 & 0.986 \\
\hline & III-IV & & & & & & & & \\
\hline \multirow[t]{2}{*}{ Tumor size } & $\geq 5 \mathrm{~cm}$ & -0.237 & 0.121 & -0.107 & 0.488 & -0.212 & 0.168 & -0.172 & 0.263 \\
\hline & $\otimes 5 \mathrm{~cm}$ & & & & & & & & \\
\hline \multirow{2}{*}{$\begin{array}{l}\text { lymph } \\
\text { nodes metastasis } \\
\text { (LNM) }\end{array}$} & Yes & -0.219 & 0.153 & -0.222 & 0.148 & -0.188 & 0.221 & 0.084 & 0.587 \\
\hline & No & & & & & & & & \\
\hline \multirow{2}{*}{$\begin{array}{l}\text { Synchronous } \\
\text { chemotherapy }\end{array}$} & Yes & 0.018 & 0.906 & -0.027 & 0.862 & 0.252 & 0.099 & -0.115 & 0.459 \\
\hline & No & & & & & & & & \\
\hline \multirow[t]{2}{*}{ Curative efficacy } & effectivity & -0.342 & 0.023 & -0.405 & 0.006 & -0.225 & 0.143 & -0.41 & 0.006 \\
\hline & inefficacy & & & & & & & & \\
\hline \multirow[t]{2}{*}{ Events } & Censored & 0.229 & 0.135 & 0.098 & 0.528 & 0.049 & 0.754 & 0.161 & 0.296 \\
\hline & Dead & & & & & & & & \\
\hline
\end{tabular}


Table2 Univariate and Multivariate analysis of various prognostic parameters in patients with esophagus cancer following Radical radiotherapy

\begin{tabular}{|c|c|c|c|c|c|c|c|c|}
\hline \multirow{3}{*}{ Variable } & \multicolumn{4}{|c|}{$\begin{array}{l}\text { Univariate } \\
\text { analysis }\end{array}$} & \multicolumn{4}{|l|}{ Multivariate analysis } \\
\hline & \multicolumn{2}{|c|}{ OSロm[ } & \multirow{2}{*}{$\begin{array}{l}\log \\
\text { Rank } \square \chi^{2}\end{array}$} & \multirow{2}{*}{$\begin{array}{l}P \\
\text { value }\end{array}$} & \multirow[t]{2}{*}{ Variable } & \multirow[t]{2}{*}{ RR } & \multirow[t]{2}{*}{$95 \% \mathrm{Cl}$} & \multirow{2}{*}{$\begin{array}{l}P \\
\text { value }\end{array}$} \\
\hline & $\mathrm{Mec}$ & an $(95 \% \mathrm{Cl})$ & & & & & & \\
\hline $\operatorname{Age}(y)$ & & & 1.314 & 0.252 & clinical stage & 2.995 & $\begin{array}{l}(1.154- \\
7.775)\end{array}$ & 0.024 \\
\hline$\geq 60$ & 15 & $\begin{array}{l}\otimes 5.734- \\
24.266 \rrbracket\end{array}$ & & & & & & \\
\hline$<60$ & 34 & $\begin{array}{l}(7.584- \\
60.416)\end{array}$ & & & & & & \\
\hline Gender & & & 0.895 & 0.344 & $\begin{array}{l}\text { Synchronous } \\
\text { chemotherapy }\end{array}$ & 0.354 & $\begin{array}{l}(0.149- \\
0.843)\end{array}$ & 0.019 \\
\hline Male & 16 & $(0-42.659)$ & & & & & & \\
\hline Female & 21 & $\begin{array}{l}(8.291- \\
33.709)\end{array}$ & & & & & & \\
\hline clinical stage & & & 3.222 & 0.073 & $\begin{array}{l}\text { Expression of NRAGE } \\
\text { nuclear }\end{array}$ & 14.536 & $\begin{array}{l}(3.847- \\
54.928)\end{array}$ & 0.000 \\
\hline III & 31 & $\begin{array}{l}₫ 6.170- \\
55.830 \rrbracket\end{array}$ & & & & & & \\
\hline III-IV & 15 & $\begin{array}{l}₫ 8.452- \\
21.548 \rrbracket\end{array}$ & & & & & & \\
\hline Tumor size & & & 0.145 & 0.704 & & & & \\
\hline$\geq 5 \mathrm{~cm}$ & 21 & $\begin{array}{l}(10.280- \\
31.720)\end{array}$ & & & & & & \\
\hline $05 \mathrm{~cm}$ & 16 & $(0-49.001)$ & & & & & & \\
\hline $\begin{array}{l}\text { lymph } \\
\text { nodes metastasis } \\
\text { (LNM) }\end{array}$ & & & 0.001 & 0.973 & & & & \\
\hline Yes & 21 & $\begin{array}{l}₫ 6.566- \\
35.434 \rrbracket\end{array}$ & & & & & & \\
\hline No & 34 & $\begin{array}{l}\otimes 1.442- \\
66.558 \rrbracket\end{array}$ & & & & & & \\
\hline $\begin{array}{l}\text { Synchronous } \\
\text { chemotherapy }\end{array}$ & & & 4.366 & 0.037 & & & & \\
\hline Yes & 41 & $\begin{array}{l}(13.456- \\
68.544)\end{array}$ & & & & & & \\
\hline No & 14 & $\begin{array}{l}(9.020- \\
18.980)\end{array}$ & & & & & & \\
\hline Curative efficacy & & & 14.831 & 0.000 & & & & \\
\hline effectivity & 24 & $\begin{array}{l}(7.702- \\
40.298)\end{array}$ & & & & & & \\
\hline inefficacy & 5 & $\begin{array}{l}(2.540- \\
7.460)\end{array}$ & & & & & & \\
\hline Expression of NRAGE & & & 1.660 & 0.198 & & & & \\
\hline
\end{tabular}




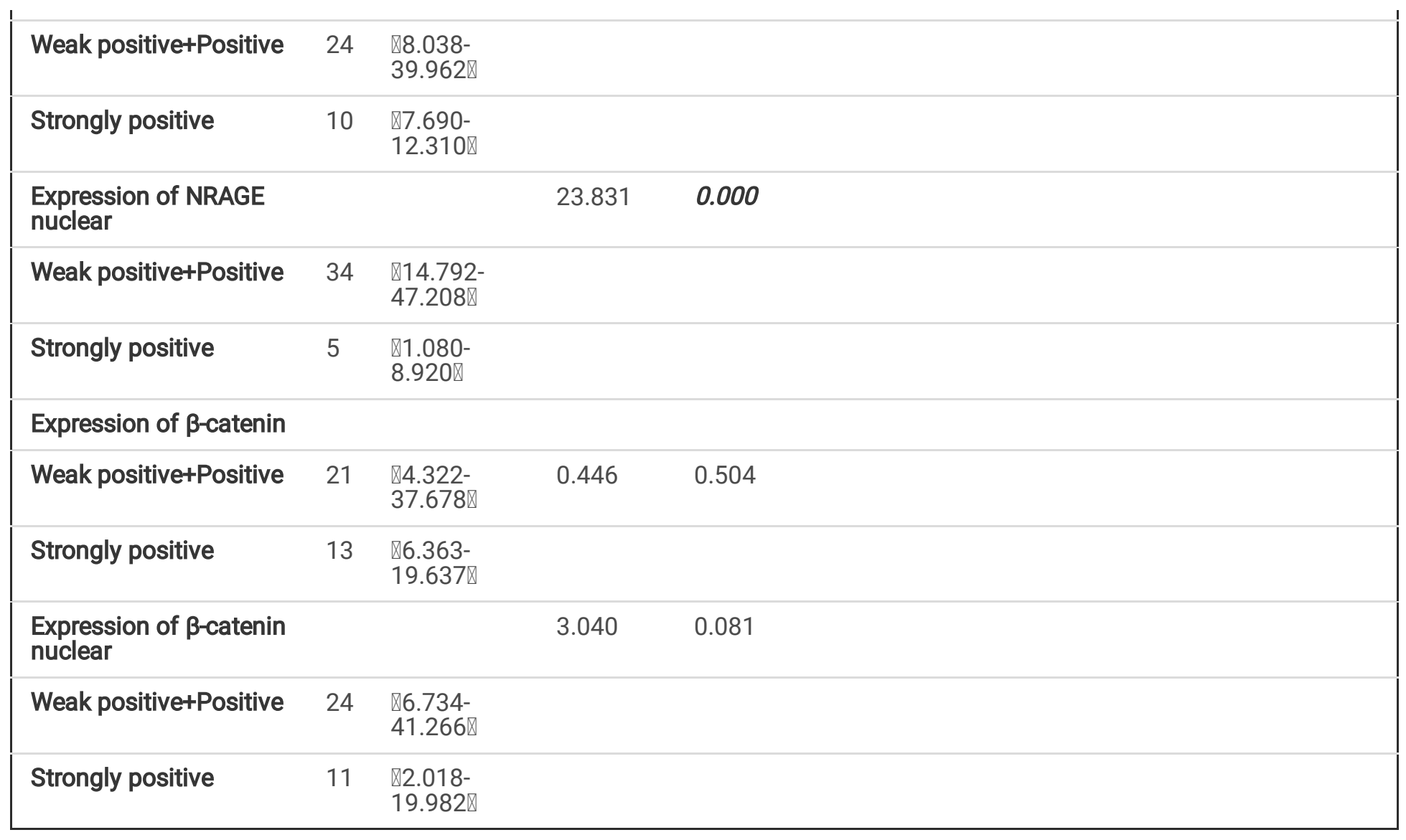

\section{Figures}


a

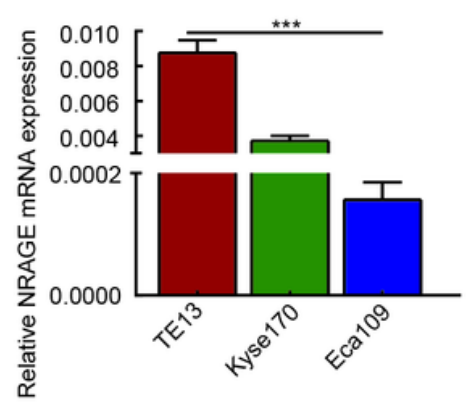

b

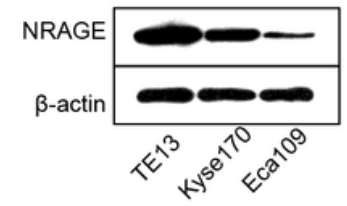

d

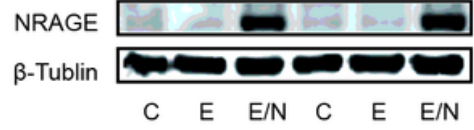

C

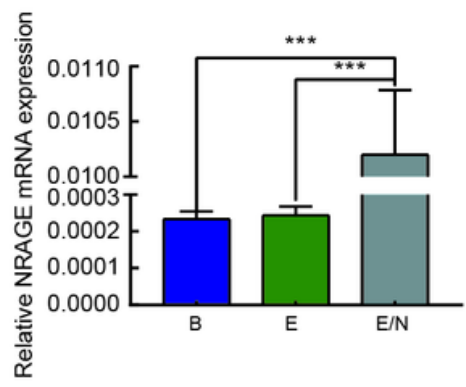

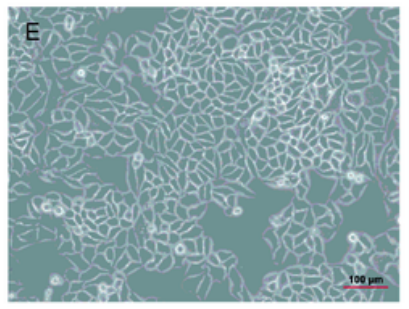

f

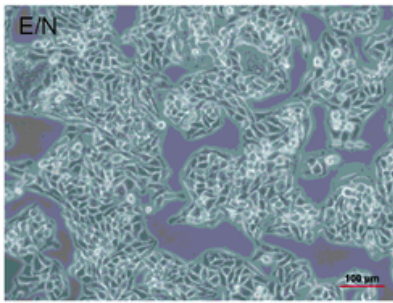

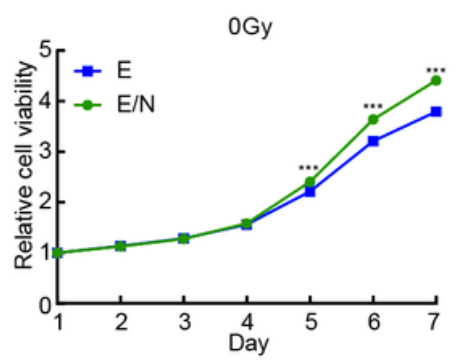

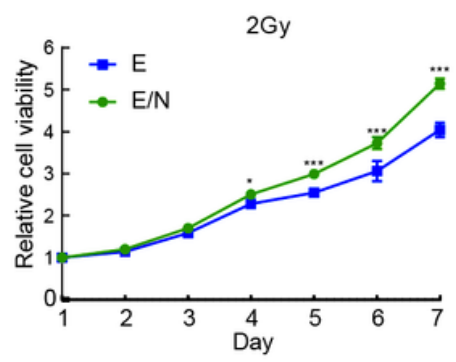

g
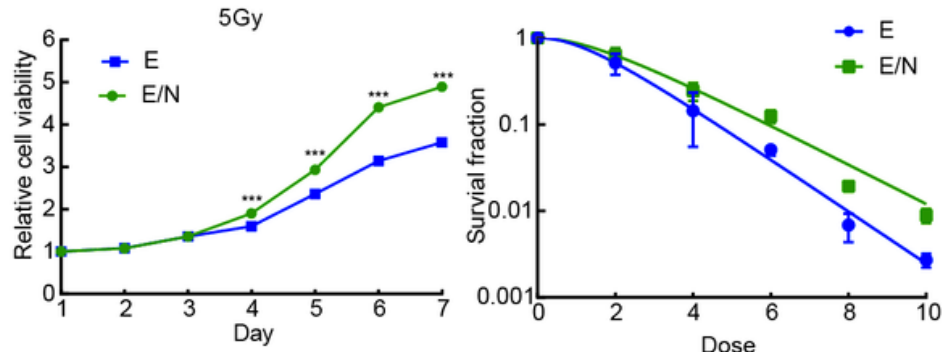

$\mathrm{h}$

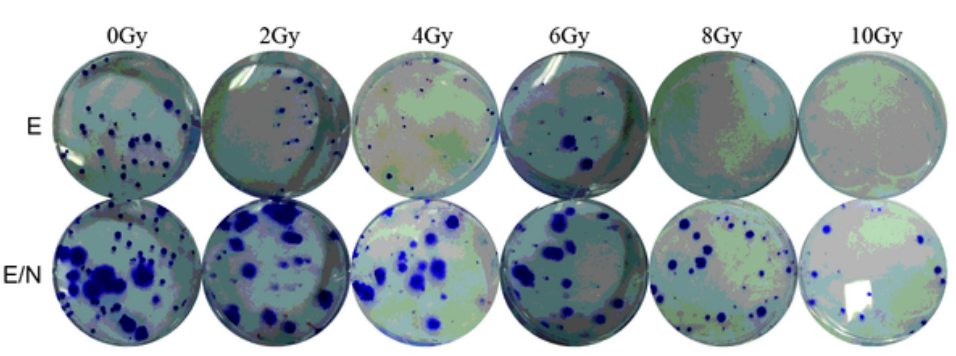

Figure 1

Overexpression of NRAGE enhanced the proliferation and radioresistance of ESCC cells in 2D culture (a) Quantification and analysis of NRAGE mRNA in different ESCC cell lines; (b)NRAGE protein levels were analyzed using western blotting in different ESCC cell lines; (c-d) Realtime PCR and Western blot assays to determine the overexpression efficiency of transduced Eca109 cells (C: Eca109; E: Eca109-vector; E/N: Eca109-NRAGE); (e) cellular morphology compared between E and E/N cells; (f) growth curve was detected by CCK8 analysis upon NRAGE stable transfection followed by different irradiation doses with 0Gy, 2Gy or 5Gy; (g) Dose-response curves were fitted according to the multi-target, single-hit model and analyzed using GraphPad Prism 8.0 software. (h) Representative images of colony formation of $\mathrm{E}$ and $\mathrm{E} / \mathrm{N}$ cells after exposure to radiation. All data represented as means \pm SD. ${ }^{\star} p<0.05$ vs. $E ;{ }^{* \star} p<0.01$ vs. $E ;{ }^{* *} p<0.001$ vs. E. 
a

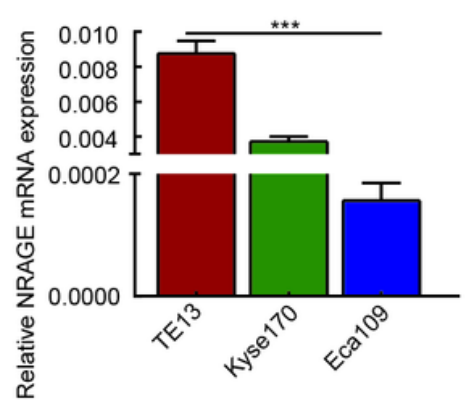

b

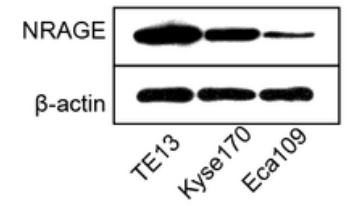

d

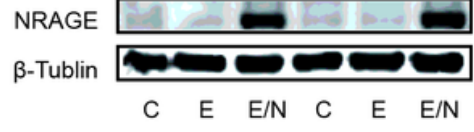

C

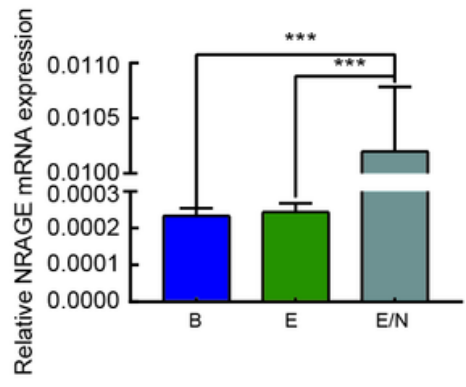

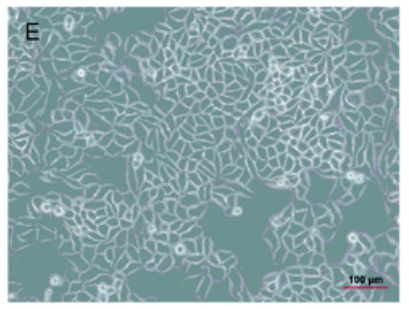

f

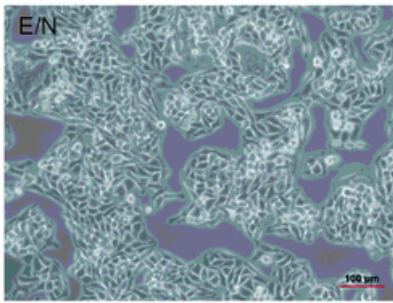

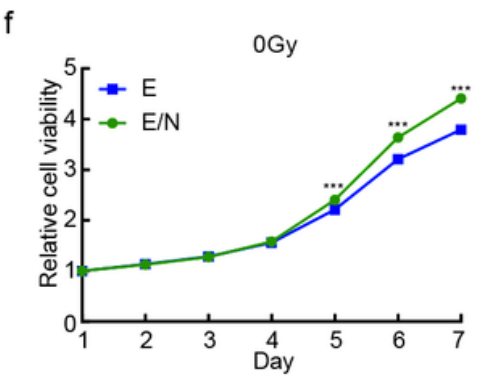

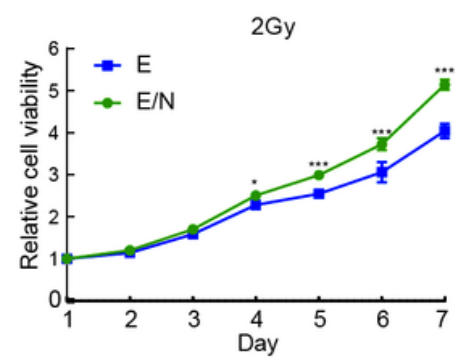

g
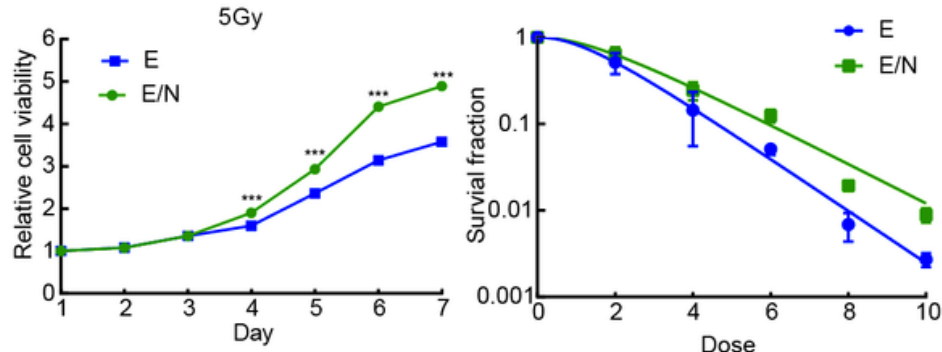

h

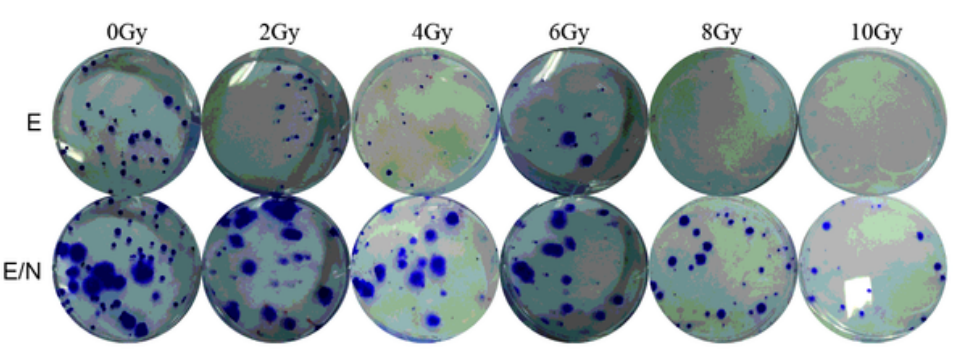

Figure 1

Overexpression of NRAGE enhanced the proliferation and radioresistance of ESCC cells in 2D culture (a) Quantification and analysis of NRAGE mRNA in different ESCC cell lines; (b)NRAGE protein levels were analyzed using western blotting in different ESCC cell lines; (c-d) Realtime PCR and Western blot assays to determine the overexpression efficiency of transduced Eca109 cells (C: Eca109; E: Eca109-vector; E/N: Eca109-NRAGE); (e) cellular morphology compared between E and E/N cells; (f) growth curve was detected by CCK8 analysis upon NRAGE stable transfection followed by different irradiation doses with 0Gy, 2Gy or 5Gy; (g) Dose-response curves were fitted according to the multi-target, single-hit model and analyzed using GraphPad Prism 8.0 software. (h) Representative images of colony formation of $\mathrm{E}$ and $\mathrm{E} / \mathrm{N}$ cells after exposure to radiation. All data represented as means \pm SD. ${ }^{\star} p<0.05$ vs. $E ;{ }^{* \star} p<0.01$ vs. $E ;{ }^{* *} p<0.001$ vs. E. 
a

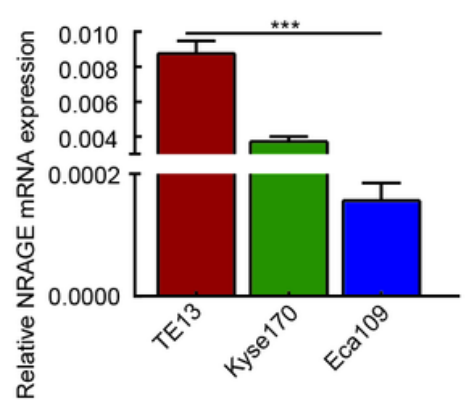

b

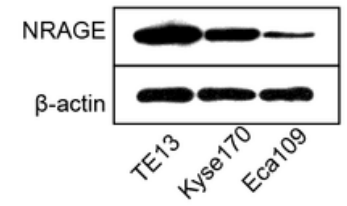

d

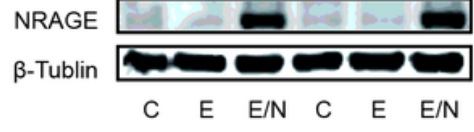

C

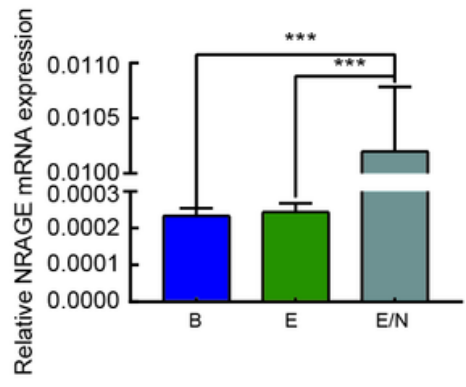

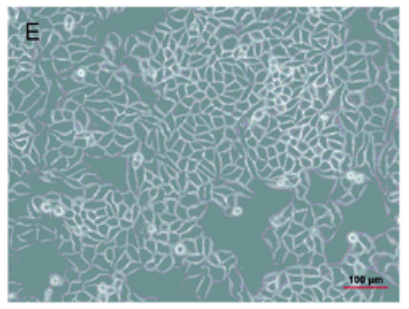

f

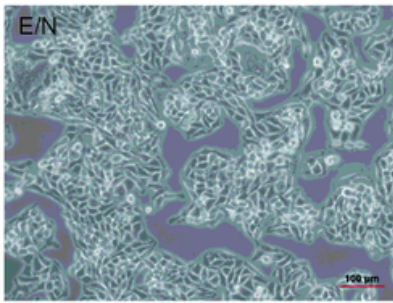

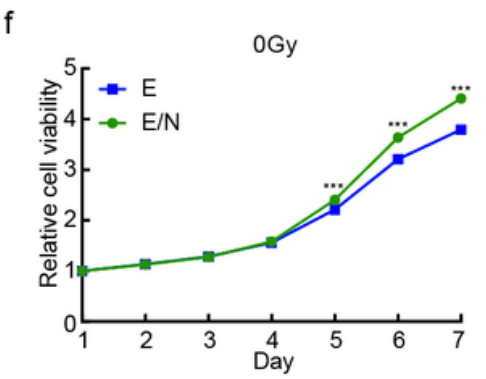

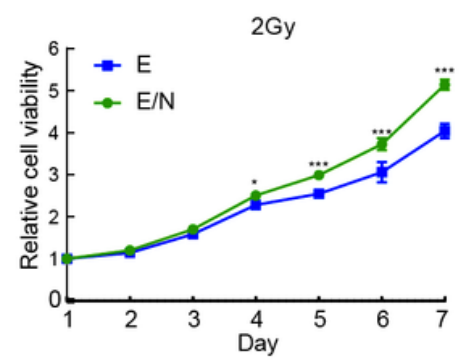

g
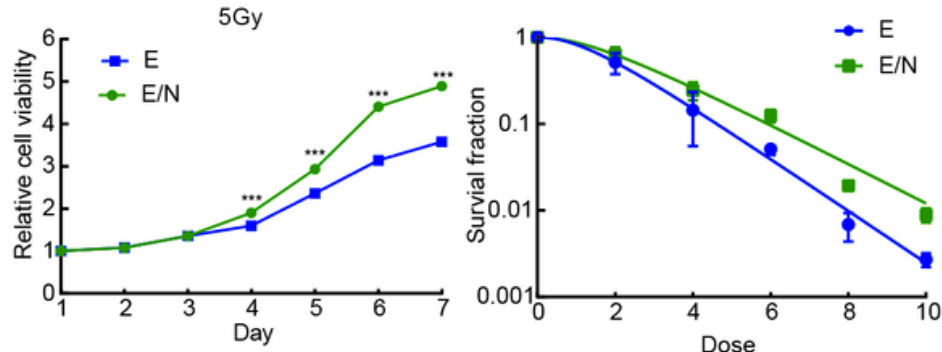

h

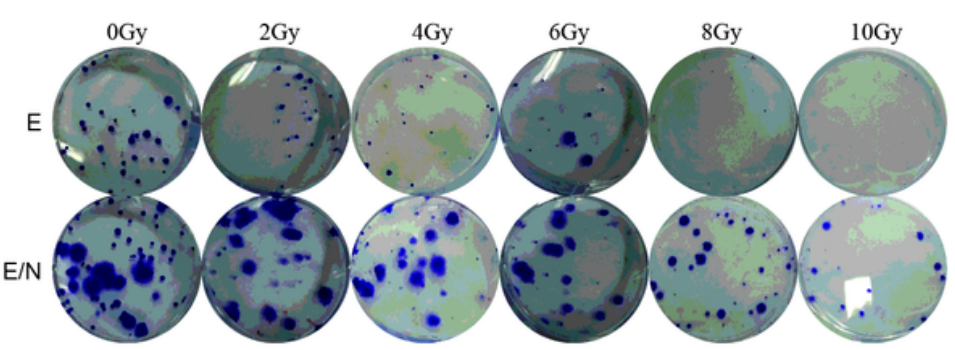

Figure 1

Overexpression of NRAGE enhanced the proliferation and radioresistance of ESCC cells in 2D culture (a) Quantification and analysis of NRAGE mRNA in different ESCC cell lines; (b)NRAGE protein levels were analyzed using western blotting in different ESCC cell lines; (c-d) Realtime PCR and Western blot assays to determine the overexpression efficiency of transduced Eca109 cells (C: Eca109; E: Eca109-vector; E/N: Eca109-NRAGE); (e) cellular morphology compared between E and E/N cells; (f) growth curve was detected by CCK8 analysis upon NRAGE stable transfection followed by different irradiation doses with 0Gy, 2Gy or 5Gy; (g) Dose-response curves were fitted according to the multi-target, single-hit model and analyzed using GraphPad Prism 8.0 software. (h) Representative images of colony formation of $\mathrm{E}$ and $\mathrm{E} / \mathrm{N}$ cells after exposure to radiation. All data represented as means \pm SD. ${ }^{\star} p<0.05$ vs. $E ;{ }^{* \star} p<0.01$ vs. $E ;{ }^{* *} p<0.001$ vs. E. 

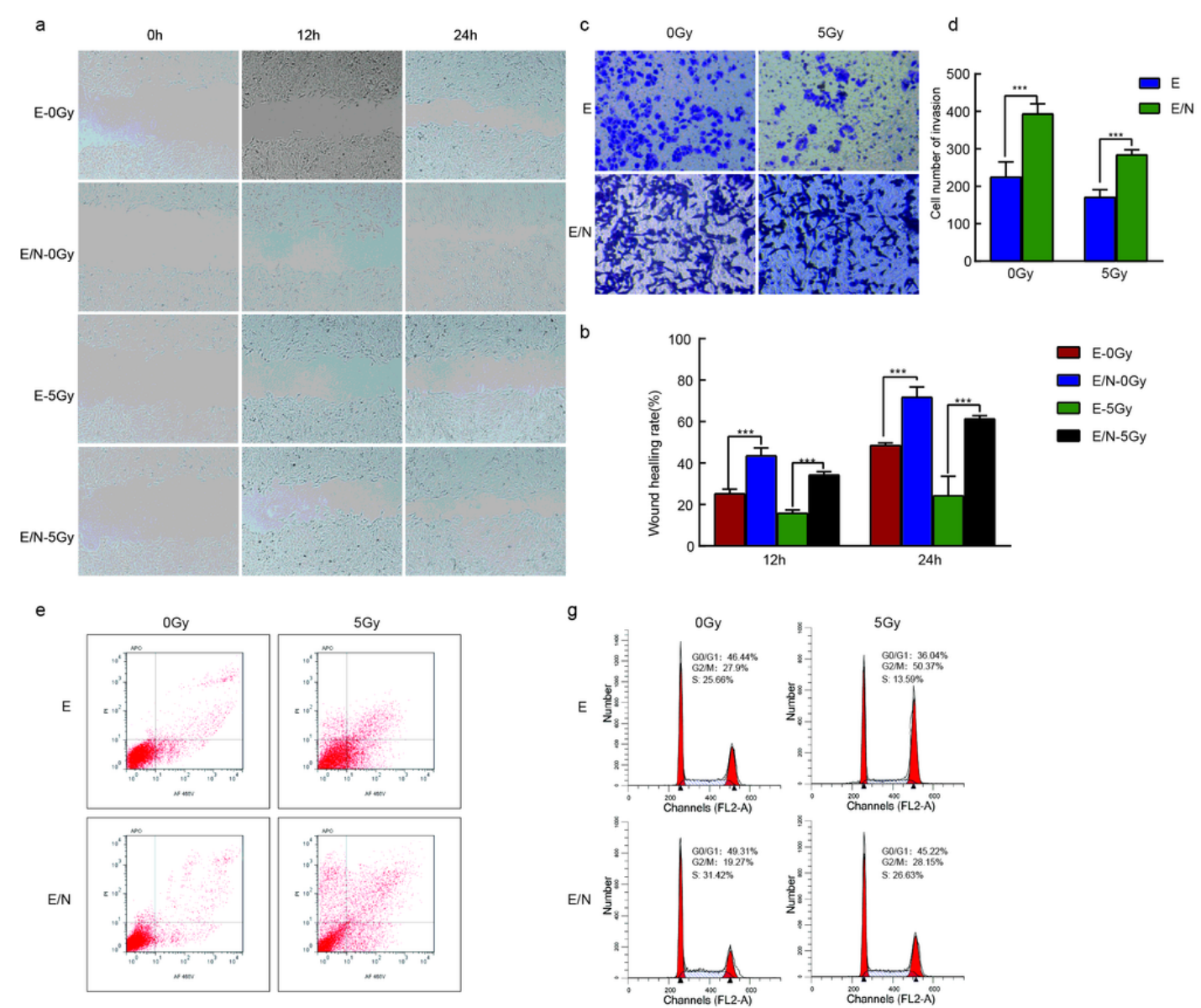

$f$
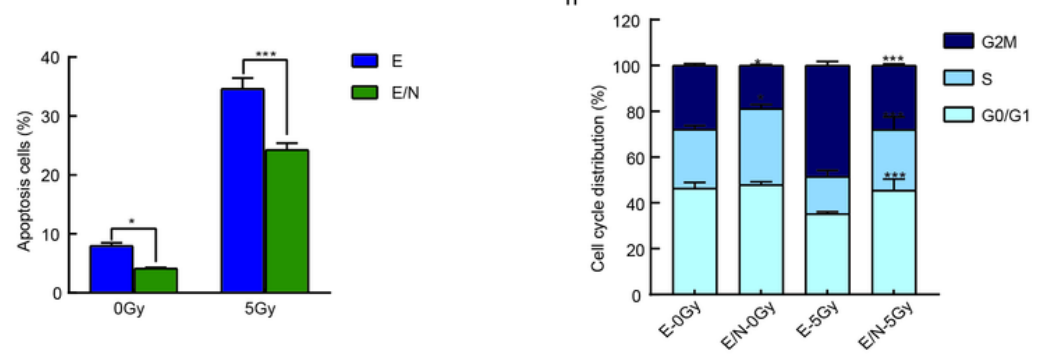

Figure 2

Overexpression of NRAGE inhibits cell migration, invasion, cell cycle progression and apoptosis after IR in 2D culture (a)Wound Healing assay was applied to test the migration ability of $\mathrm{E}$ and $\mathrm{E} / \mathrm{N}$ with or without $5 \mathrm{~Gy}$ irradiation (magnification: 200x); (b) Quantitative assessment of wound-healing rate at the different times (12h and 24h); (c) Matrigel invasion assay was applied to compare $\mathrm{E}$ and $\mathrm{E} / \mathrm{N}$ cells for invasion ability with or without 5Gy irradiation (magnification: 200x ); (d) Quantitative assessment of the number of invasion cells. ${ }^{*} \mathrm{P}<0.05$ vs. $\mathrm{E} ;{ }^{*} \mathrm{P}<0.01 \mathrm{vs}$. $\mathrm{E} ;{ }^{* \star *} \mathrm{P}<0.005 \mathrm{vs}$. $\mathrm{E}$; (e) Annexin V-FITC/PI staining was applied to test the apoptotic rates of $\mathrm{E}$ and $\mathrm{E} / \mathrm{N}$ cells with or without $5 \mathrm{~Gy}$ IR by flow cytometry; (f) Quantitative assessment of the apoptotic rates; (g) Propidium iodide stain was applied to test cell cycle of $\mathrm{E}$ and $\mathrm{E} / \mathrm{N}$ cells with or without 5 Gy IR by flow cytometric; (h) Cell cycle distributions were analyzed using GraphPad Prism 5.0 software; All data represented as means \pm SD. ${ }^{*} \mathrm{p}<0.05$ vs. $\mathrm{E} ;{ }^{* *} \mathrm{p}<0.01$ vs. $\mathrm{E} ;{ }^{* * *} \mathrm{p}<0.001$ vs. E. 

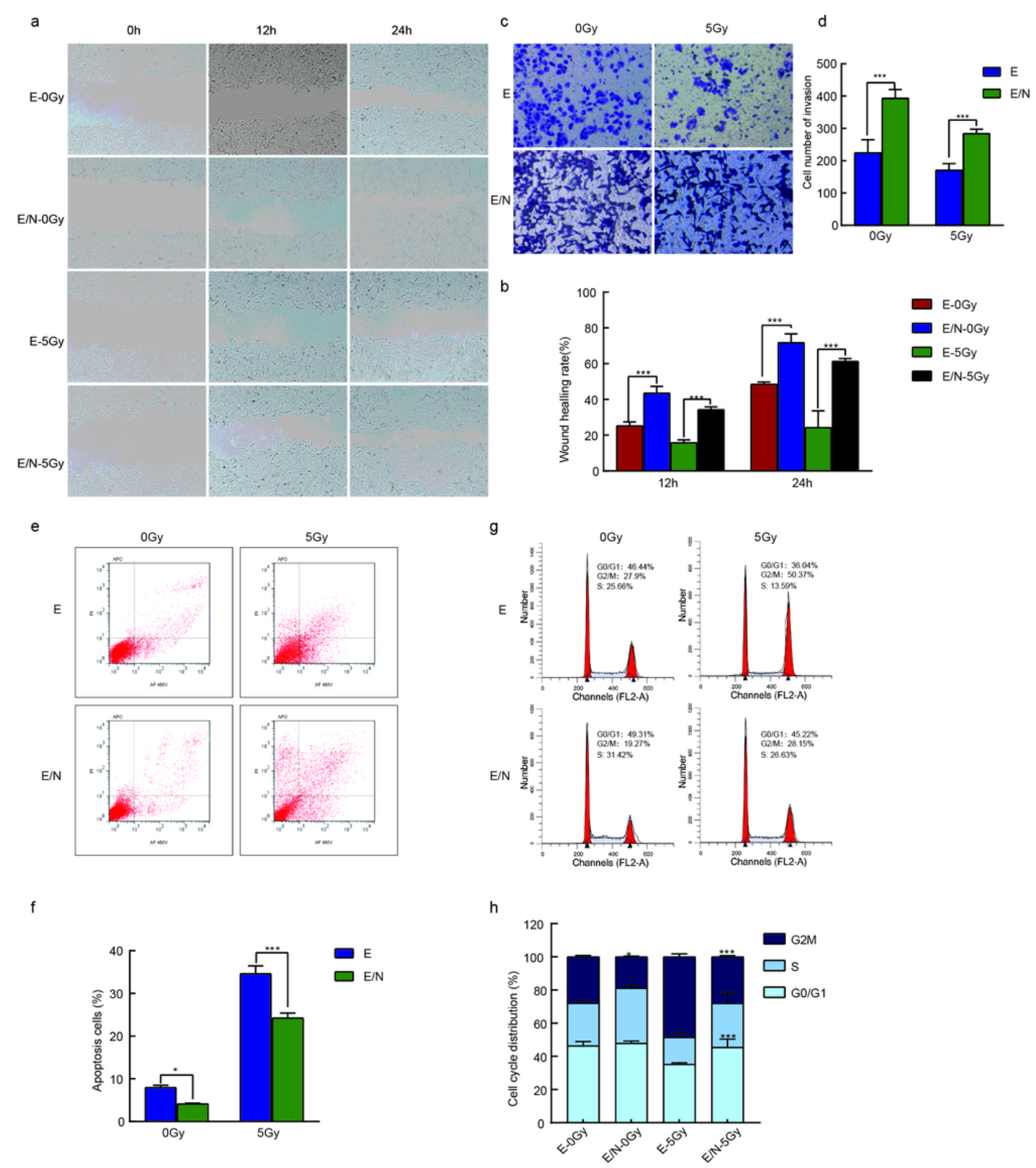

\section{Figure 2}

Overexpression of NRAGE inhibits cell migration, invasion, cell cycle progression and apoptosis after IR in 2D culture (a)Wound Healing assay was applied to test the migration ability of $\mathrm{E}$ and $\mathrm{E} / \mathrm{N}$ with or without $5 \mathrm{~Gy}$ irradiation (magnification: 200x); (b) Quantitative assessment of wound-healing rate at the different times (12h and 24h); (c) Matrigel invasion assay was applied to compare $\mathrm{E}$ and $\mathrm{E} / \mathrm{N}$ cells for invasion ability with or without 5Gy irradiation (magnification: 200x ); (d) Quantitative assessment of the number of invasion cells. ${ }^{*} \mathrm{P}<0.05$ vs. $\mathrm{E} ;{ }^{*} \mathrm{P}<0.01 \mathrm{vs}$. $\mathrm{E} ;{ }^{* \star *} \mathrm{P}<0.005 \mathrm{vs}$. $\mathrm{E}$; (e) Annexin V-FITC/PI staining was applied to test the apoptotic rates of $\mathrm{E}$ and $\mathrm{E} / \mathrm{N}$ cells with or without $5 \mathrm{~Gy}$ IR by flow cytometry; (f) Quantitative assessment of the apoptotic rates; (g) Propidium iodide stain was applied to test cell cycle of $\mathrm{E}$ and E/N cells with or without 5 Gy IR by flow cytometric; (h) Cell cycle distributions were analyzed using GraphPad Prism 5.0 software; All data represented as means \pm SD. ${ }^{*} p<0.05$ vs. $E ;{ }^{* \star} p<0.01$ vs. $E ;{ }^{* \star *} p<0.001$ vs. E. 

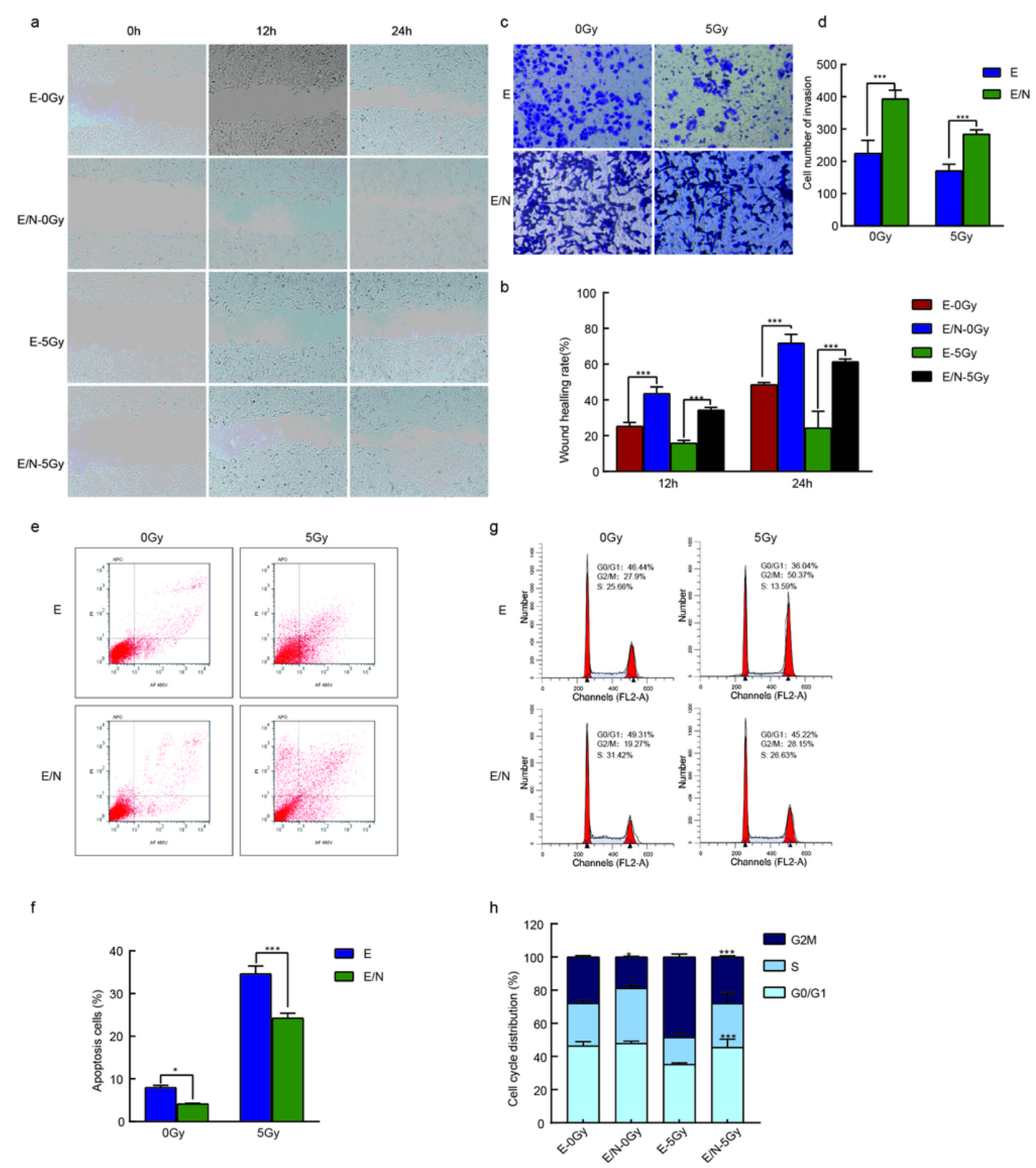

\section{Figure 2}

Overexpression of NRAGE inhibits cell migration, invasion, cell cycle progression and apoptosis after IR in 2D culture (a)Wound Healing assay was applied to test the migration ability of $\mathrm{E}$ and $\mathrm{E} / \mathrm{N}$ with or without $5 \mathrm{~Gy}$ irradiation (magnification: 200x); (b) Quantitative assessment of wound-healing rate at the different times (12h and 24h); (c) Matrigel invasion assay was applied to compare $\mathrm{E}$ and $\mathrm{E} / \mathrm{N}$ cells for invasion ability with or without 5Gy irradiation (magnification: 200x ); (d) Quantitative assessment of the number of invasion cells. ${ }^{*} \mathrm{P}<0.05$ vs. $\mathrm{E} ;{ }^{*} \mathrm{P}<0.01 \mathrm{vs}$. $\mathrm{E} ;{ }^{* \star *} \mathrm{P}<0.005 \mathrm{vs}$. $\mathrm{E}$; (e) Annexin V-FITC/PI staining was applied to test the apoptotic rates of $\mathrm{E}$ and $\mathrm{E} / \mathrm{N}$ cells with or without $5 \mathrm{~Gy}$ IR by flow cytometry; (f) Quantitative assessment of the apoptotic rates; (g) Propidium iodide stain was applied to test cell cycle of $\mathrm{E}$ and E/N cells with or without 5 Gy IR by flow cytometric; (h) Cell cycle distributions were analyzed using GraphPad Prism 5.0 software; All data represented as means \pm SD. ${ }^{*} p<0.05$ vs. $E ;{ }^{* \star} p<0.01$ vs. $E ;{ }^{* \star *} p<0.001$ vs. E. 
a

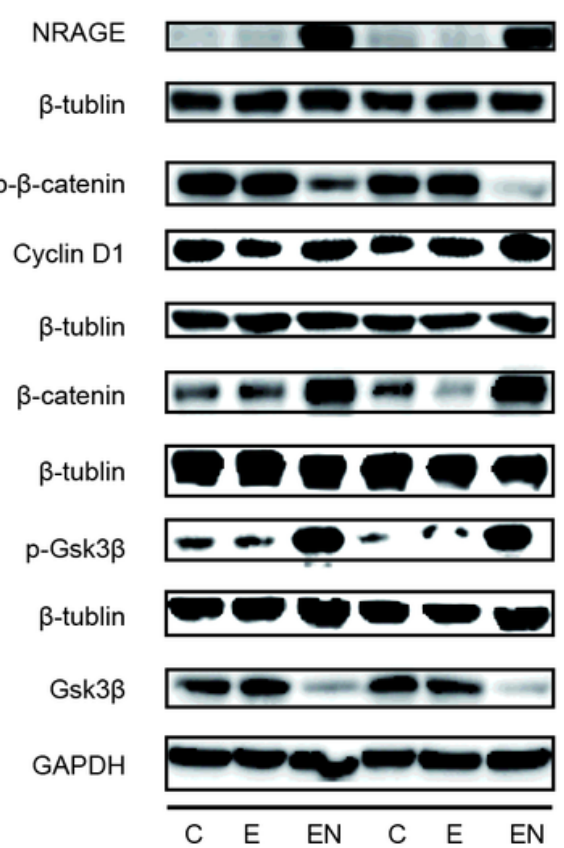

b

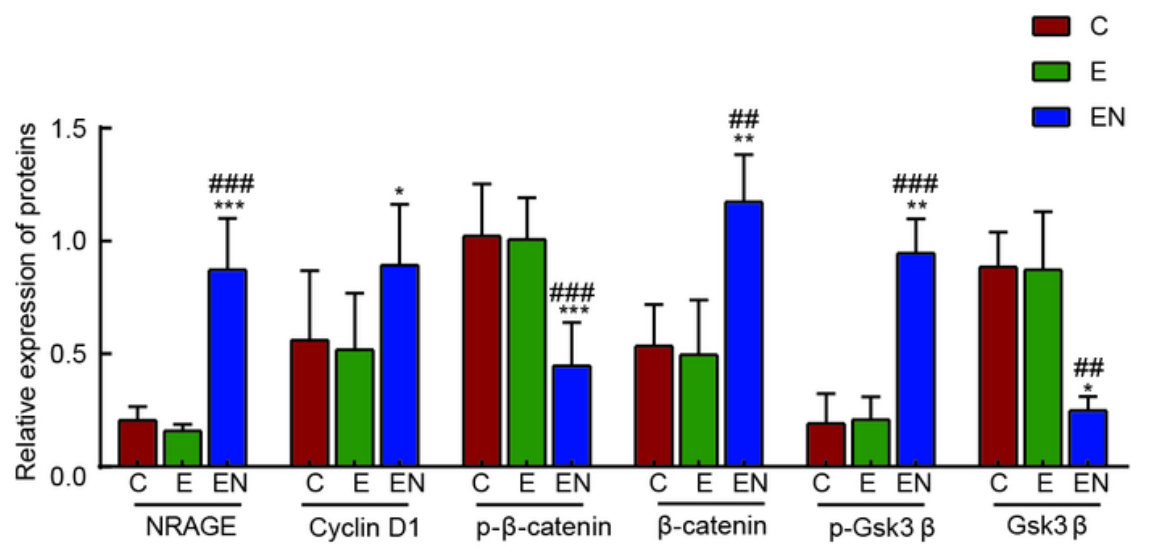

\section{Figure 3}

Overexpression of NRAGE activates canonical Wnt signaling pathways in ESCC cells with 2D culture (a)Expression of Wnt/ $\beta$ catenin signaling pathway-related proteins was determined using western blotting; (b) Quantitative assessment of related proteins in Wnt/ $\beta$-catenin signaling pathway. All data represented as means $\pm S D$. ${ }^{\star} p<0.05$ vs. $E ;{ }^{* \star} p<0.01$ vs. $E ;{ }^{\star \star \star *} p<0.001$ vs. $E$, $\#$ p $<0.05$ vs. C; \#\# p<0.01 vs. C; \#\#\# p<0.001 vs. C

a

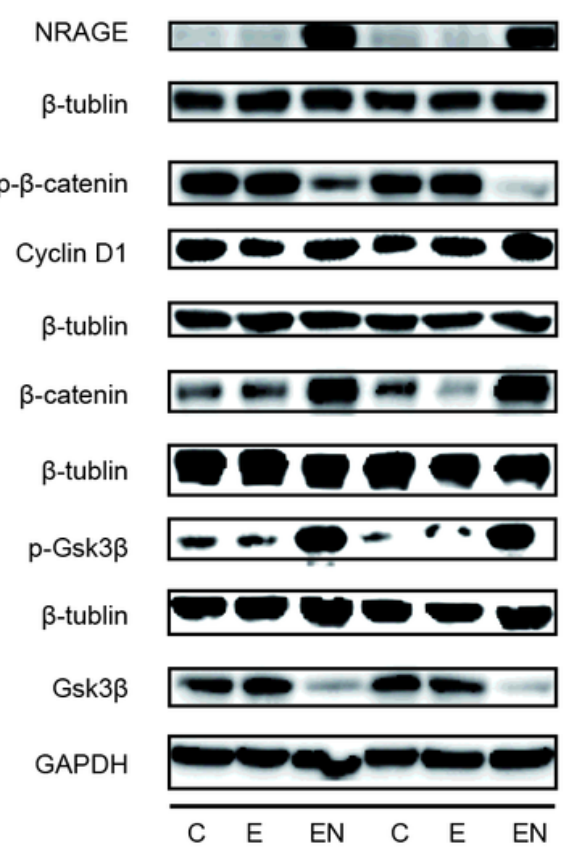

b

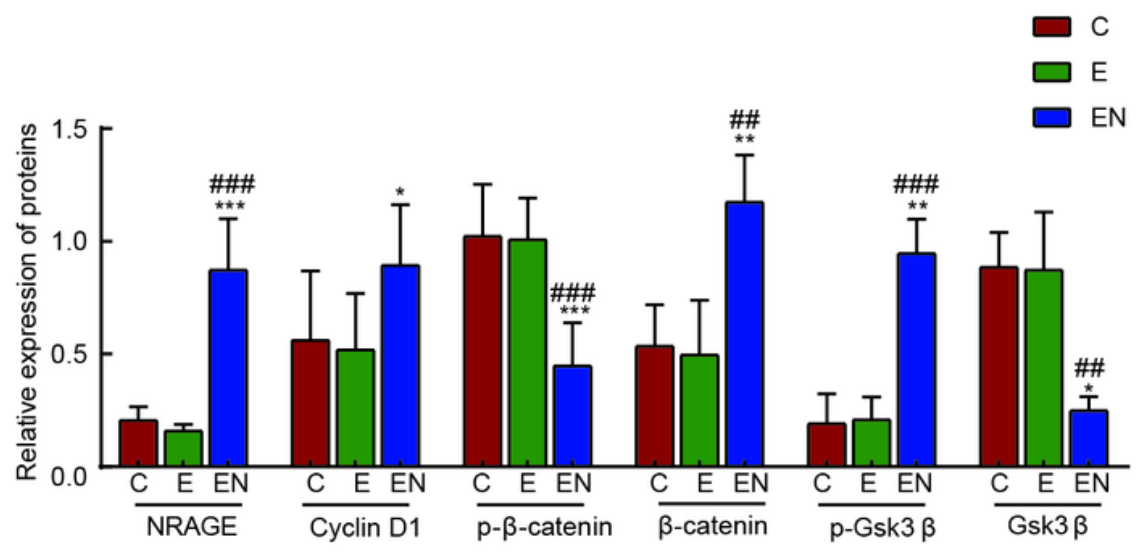

Figure 3 
Overexpression of NRAGE activates canonical Wnt signaling pathways in ESCC cells with 2D culture (a)Expression of Wnt/ $\beta$ catenin signaling pathway-related proteins was determined using western blotting; (b) Quantitative assessment of related proteins in Wnt/ $\beta$-catenin signaling pathway. All data represented as means $\pm S D$. ${ }^{\star} p<0.05$ vs. $E ;{ }^{* \star} p<0.01$ vs. $E ;{ }^{* \star \star} p<0.001$ vs. E, \# $p<0.05$ vs. C; \#\# p<0.01 vs. C; \#\#\# p<0.001 vs. C

a

$$
\text { NRAGE }
$$

$\beta$-tublin

p- $\beta$-catenin

Cyclin D1

$\beta$-tublin

$\beta$-catenin

$\beta$-tublin

p-Gsk3 3

$\beta$-tublin

Gsk3ß

GAPDH b

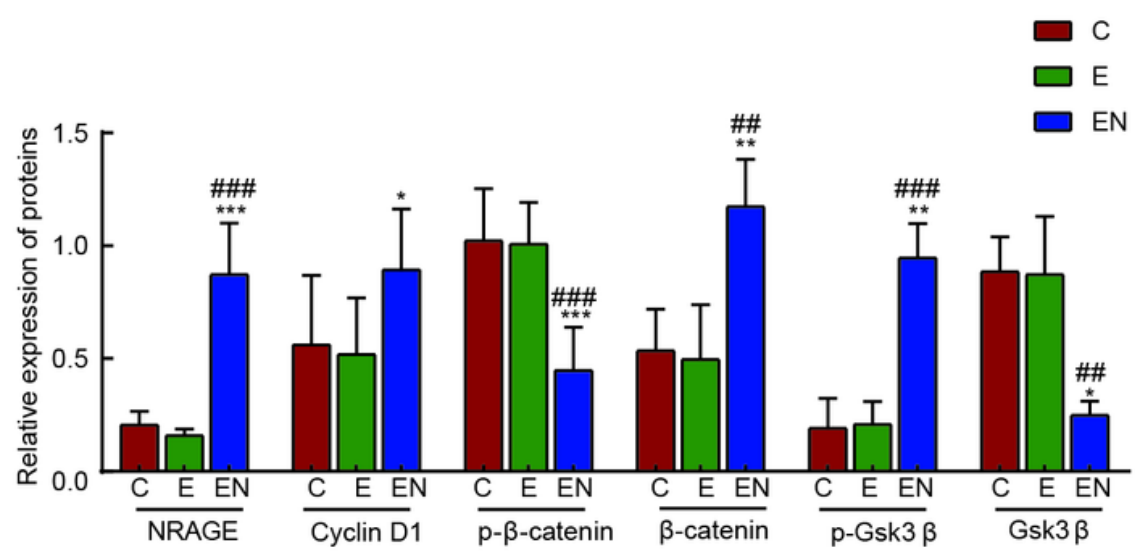

\section{Figure 3}

Overexpression of NRAGE activates canonical Wnt signaling pathways in ESCC cells with 2D culture (a)Expression of Wnt/ $\beta$ catenin signaling pathway-related proteins was determined using western blotting; (b) Quantitative assessment of related proteins in Wnt/ $\beta$-catenin signaling pathway. All data represented as means $\pm S D$. ${ }^{\star} p<0.05$ vs. $E ;{ }^{* \star} p<0.01$ vs. $E ;{ }^{* \star *} p<0.001$ vs. E, $\# p<0.05$ vs. C; \#\# p<0.01 vs. C; \#\#\# p<0.001 vs. C 
a

e
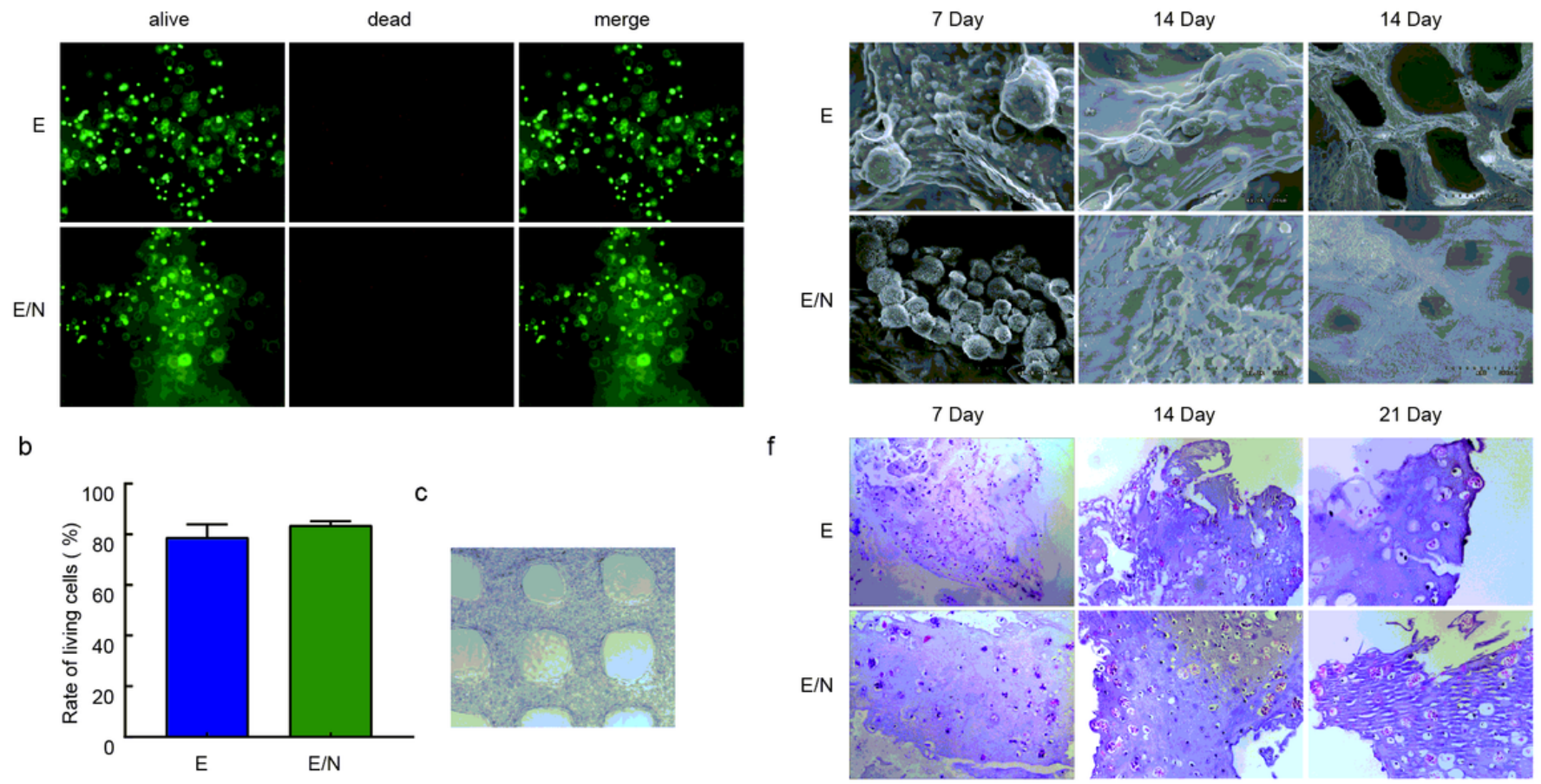

d

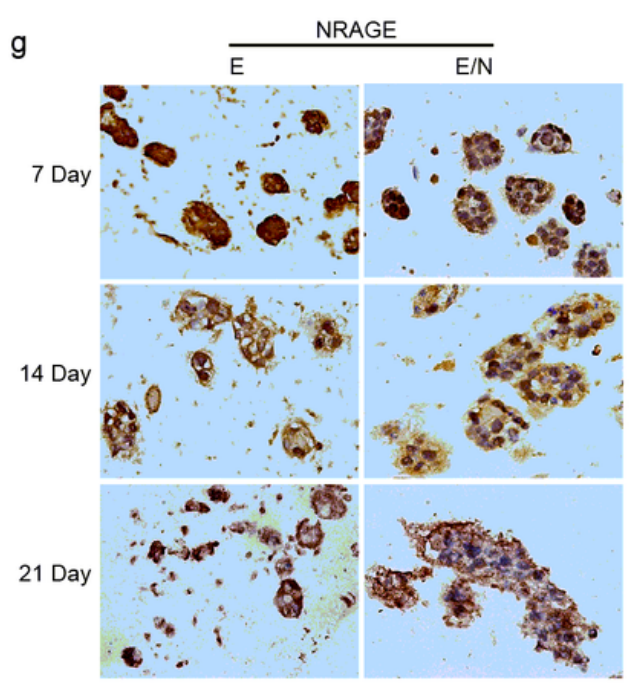

Figure 4

3D bioprinted ESCC cell-laden system cultured in vitro (a) Live/dead staining for cell viability after printing, where live cells are stained in green and dead cells in red; (b) Cell viability of $\mathrm{E}$ and $\mathrm{E} / \mathrm{N}$ cells after printing. (c) 3D bioprinted $\mathrm{E}$ and $\mathrm{E} / \mathrm{N}$ cells at day 1 of culturing. (d) optical microscopy images; (e) SEM images; (f) Hematoxylin-eosin staining: 3D bioprinted E and E/N cells cultured in vitro for 7d, 14d and 21d; (g囚Immunohistochemistry of 3D bioprinted E and E/N cells: NRAGE expression at 7, 14,

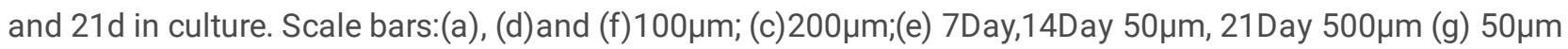


a

e
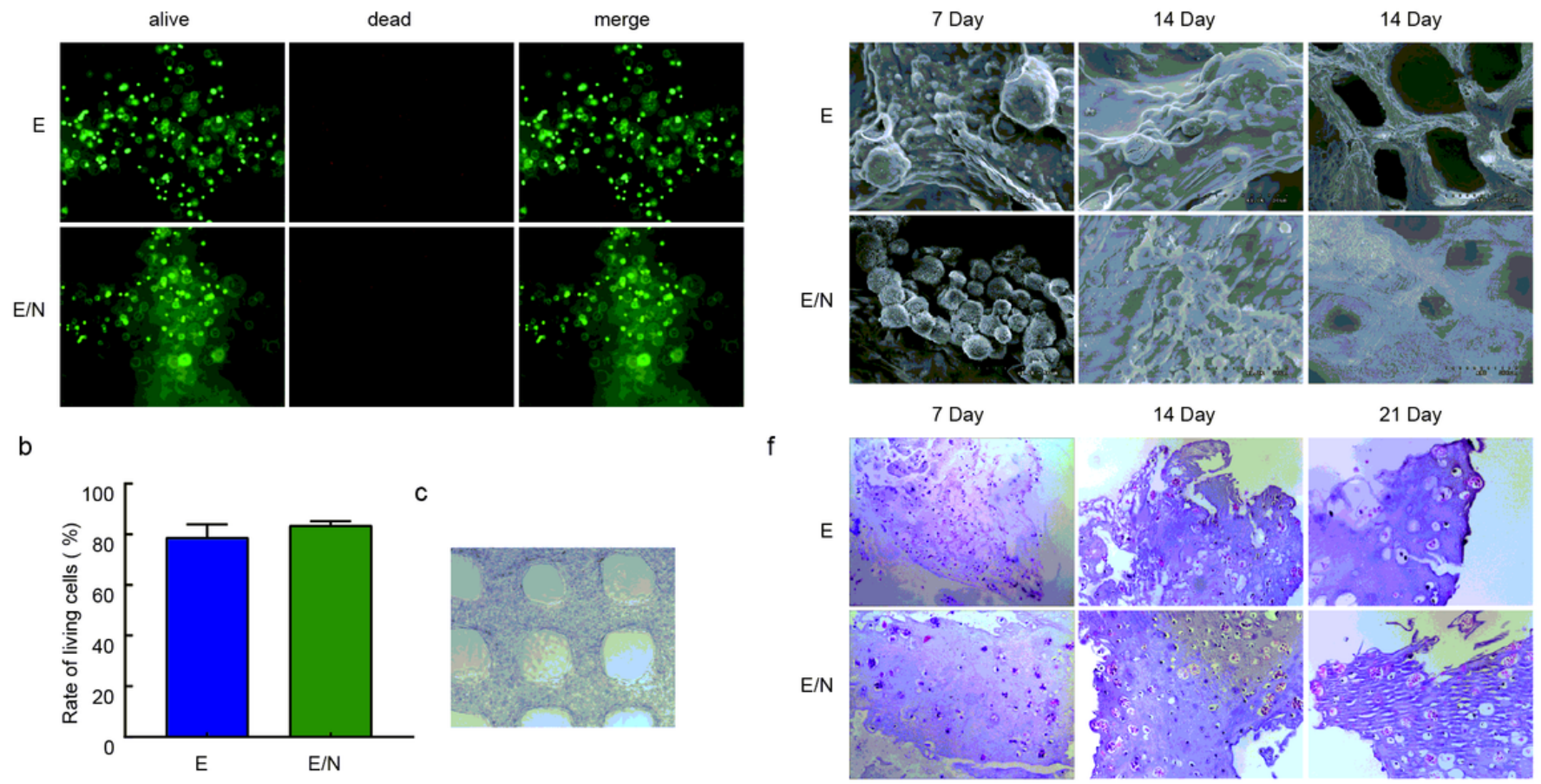

d

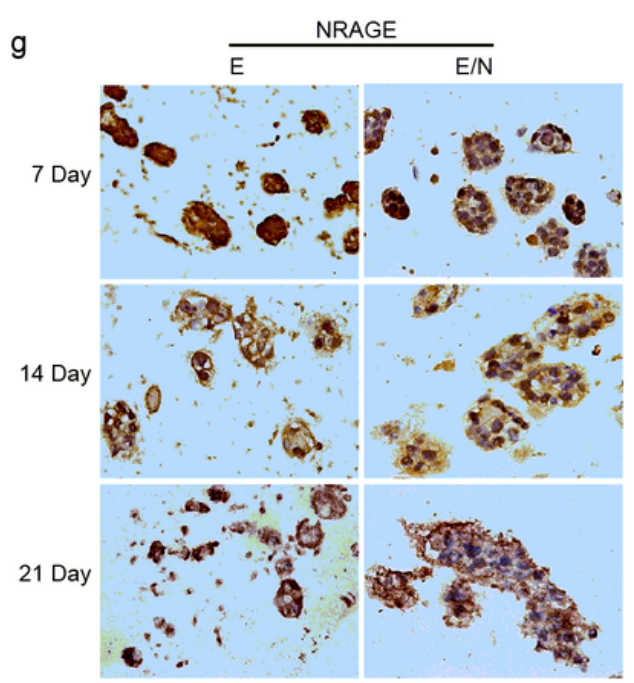

Figure 4

3D bioprinted ESCC cell-laden system cultured in vitro (a) Live/dead staining for cell viability after printing, where live cells are stained in green and dead cells in red; (b) Cell viability of $\mathrm{E}$ and $\mathrm{E} / \mathrm{N}$ cells after printing. (c) 3D bioprinted $\mathrm{E}$ and $\mathrm{E} / \mathrm{N}$ cells at day 1 of culturing. (d) optical microscopy images; (e) SEM images; (f) Hematoxylin-eosin staining: 3D bioprinted E and E/N cells cultured in vitro for 7d, 14d and 21d; (g囚Immunohistochemistry of 3D bioprinted E and E/N cells: NRAGE expression at 7, 14,

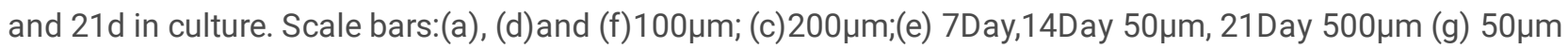


a

e
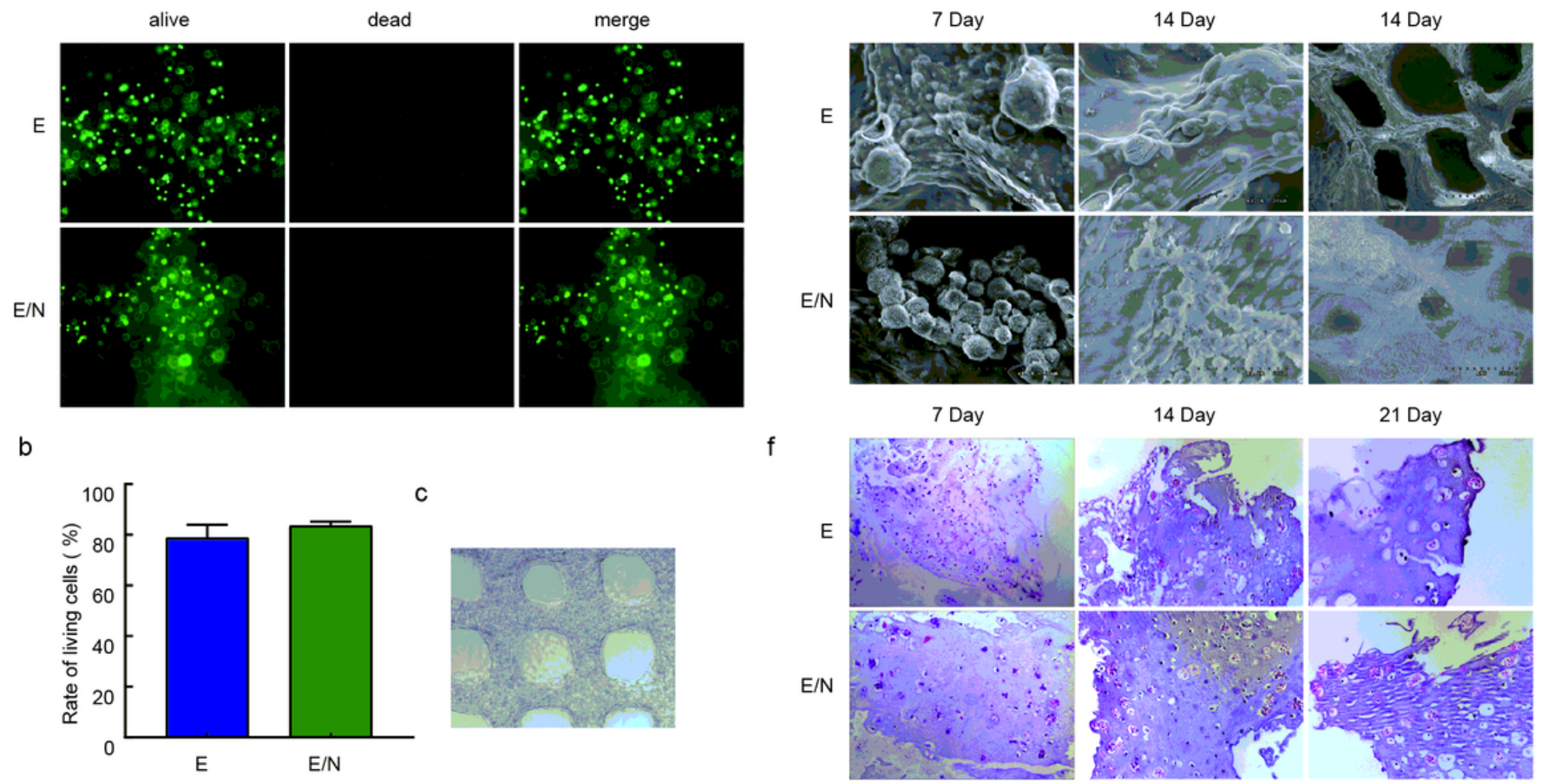

d

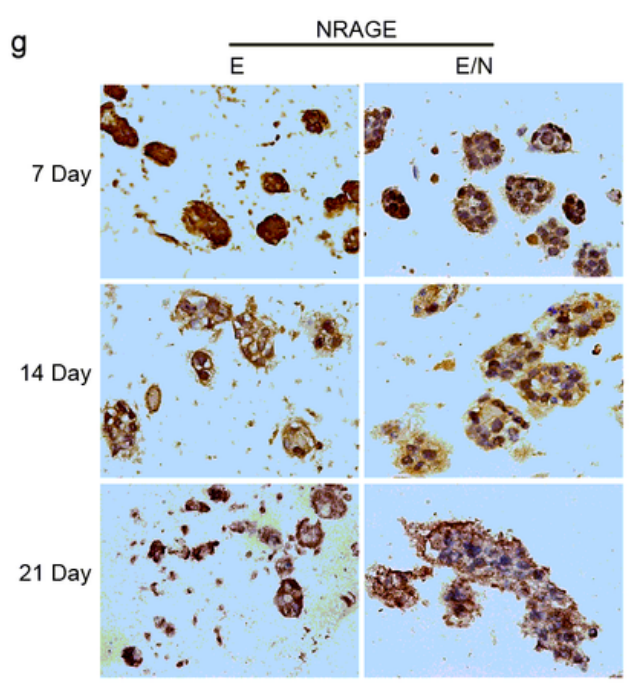

Figure 4

3D bioprinted ESCC cell-laden system cultured in vitro (a) Live/dead staining for cell viability after printing, where live cells are stained in green and dead cells in red; (b) Cell viability of $\mathrm{E}$ and $\mathrm{E} / \mathrm{N}$ cells after printing. (c) 3D bioprinted $\mathrm{E}$ and $\mathrm{E} / \mathrm{N}$ cells at day 1 of culturing. (d) optical microscopy images; (e) SEM images; (f) Hematoxylin-eosin staining: 3D bioprinted E and E/N cells cultured in vitro for 7d, 14d and 21d; (g囚Immunohistochemistry of 3D bioprinted E and E/N cells: NRAGE expression at 7, 14,

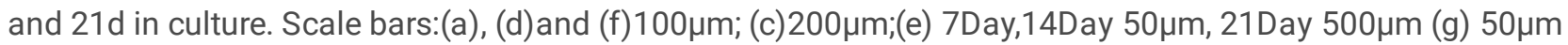




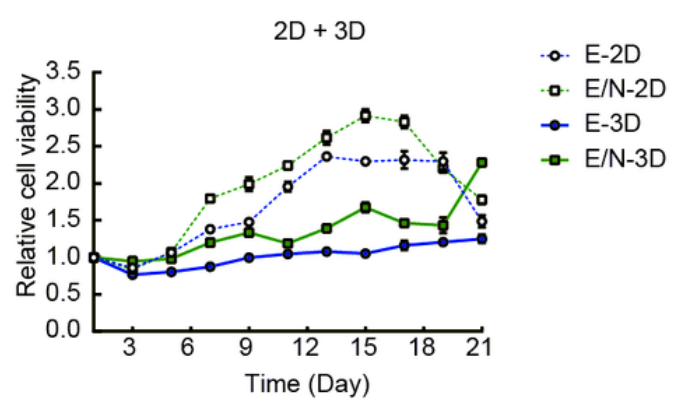

C

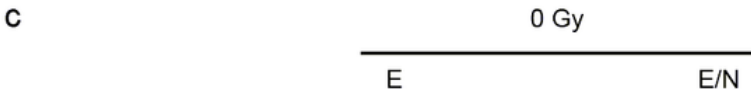

b
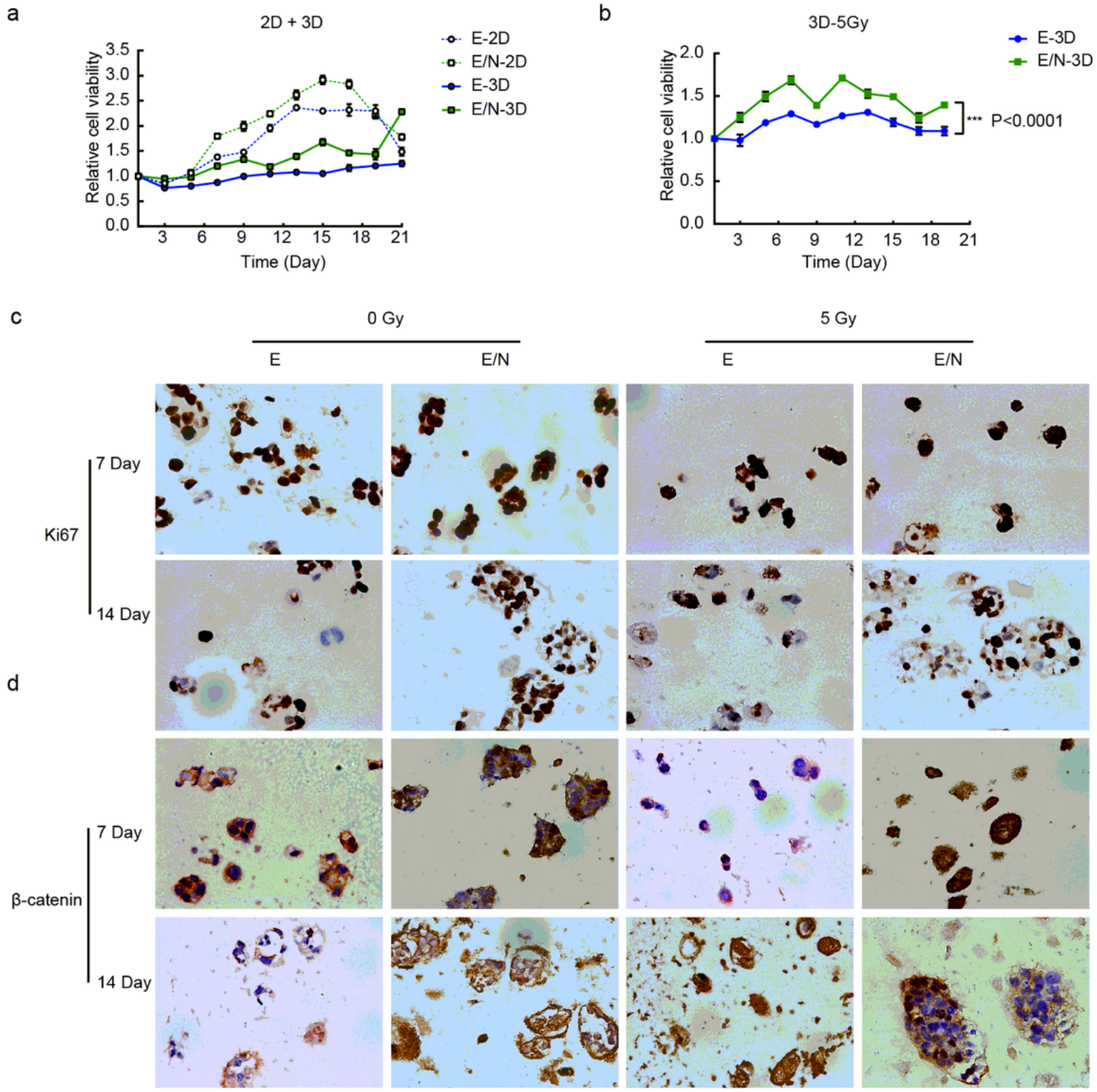

Figure 5

Overexpression of NRAGE enhanced the proliferation and radioresistance of ESCC cells in 3D bioprinted hydrogels (a) Comparing cell proliferation between $\mathrm{E}$ and $\mathrm{E} / \mathrm{N}$ in 2D and 3D by Alamar Blue assays; (b) Cell proliferation was tested by immunohistochemistry of 3D bioprinted $\mathrm{E}$ and $\mathrm{E} / \mathrm{N}$ cells: Ki-67 expression at 7,14, and 21d in culture with or without IR; (c) cell viability between $\mathrm{E}$ and $\mathrm{E} / \mathrm{N}$ in 3D after $5 \mathrm{~Gy}$ IR by Alamar Blue assays; (d) Immunohistochemistry of 3D bioprinted $\mathrm{E}$ and $\mathrm{E} / \mathrm{N}$ cells: $\beta$-catenin expression at 7,14, and 21d in culture with or without IR. Scale bars: (b) and (d) $50 \mu \mathrm{m}$, all data represented as means $\pm S D$. ${ }^{*} p<0.05$ vs. $E ;{ }^{* \star} p<0.01$ vs. $E ;{ }^{\star \star \star *} p<0.001 v s$. $E$. 


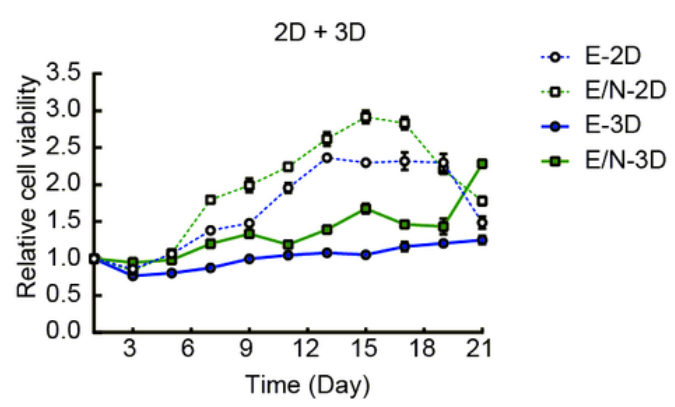

C

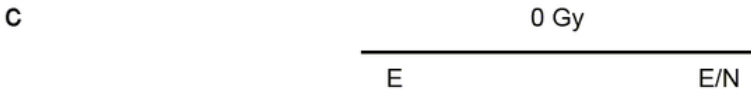

b

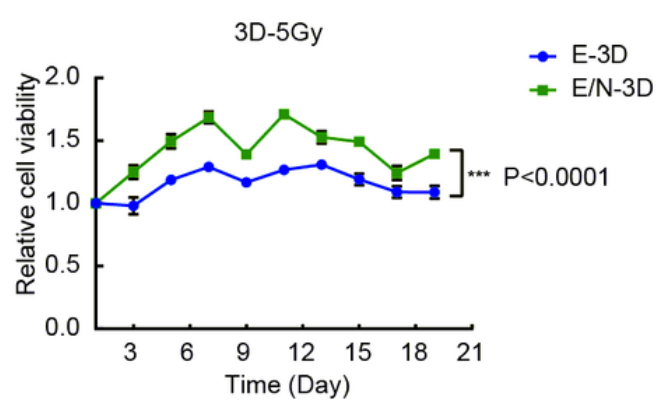

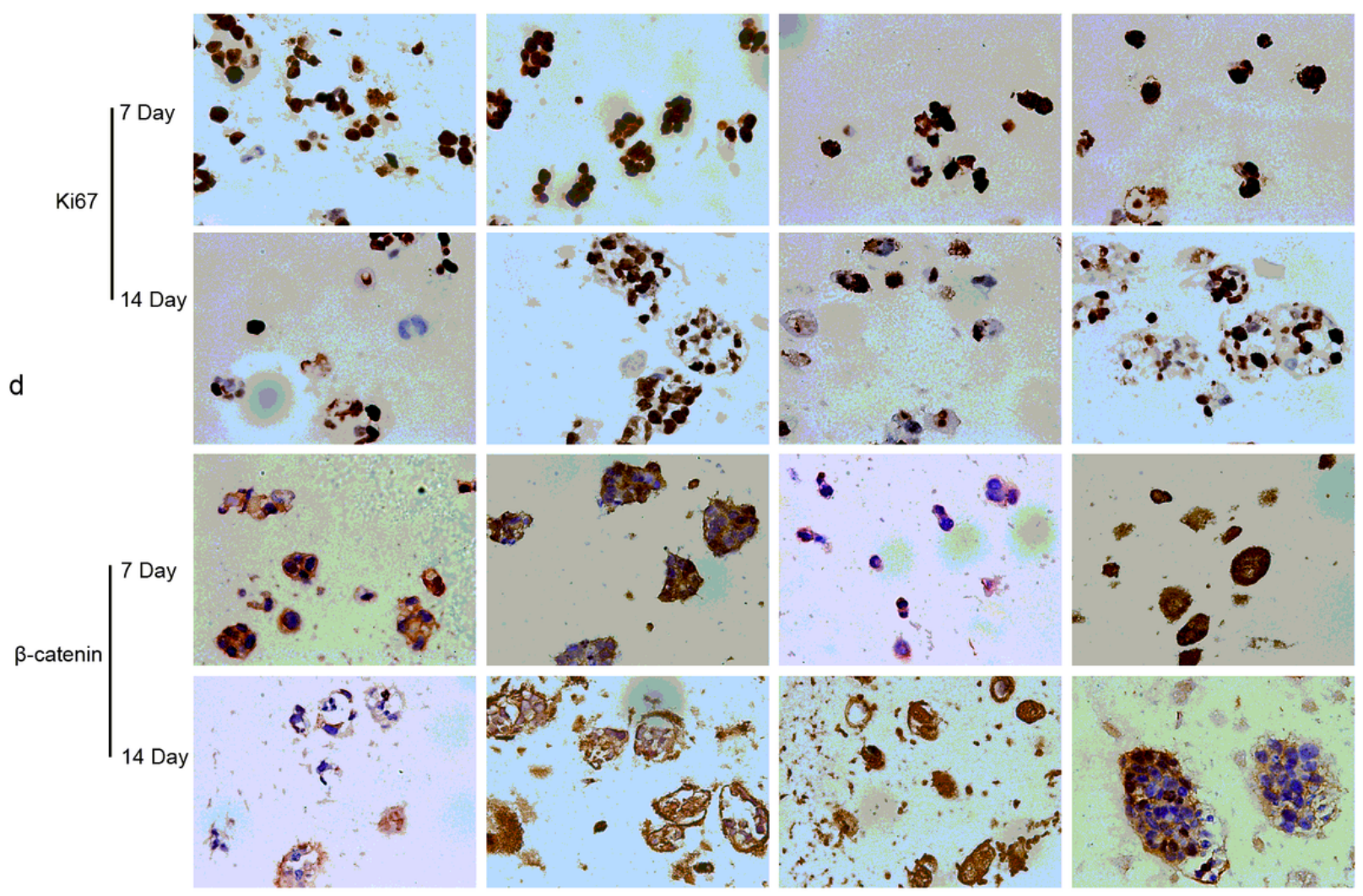

Figure 5

Overexpression of NRAGE enhanced the proliferation and radioresistance of ESCC cells in 3D bioprinted hydrogels (a) Comparing cell proliferation between $\mathrm{E}$ and $\mathrm{E} / \mathrm{N}$ in 2D and 3D by Alamar Blue assays; (b) Cell proliferation was tested by immunohistochemistry of 3D bioprinted $\mathrm{E}$ and $\mathrm{E} / \mathrm{N}$ cells: Ki-67 expression at 7,14, and 21d in culture with or without IR; (c) cell viability between $\mathrm{E}$ and $\mathrm{E} / \mathrm{N}$ in 3D after $5 \mathrm{~Gy}$ IR by Alamar Blue assays; (d) Immunohistochemistry of 3D bioprinted $\mathrm{E}$ and $\mathrm{E} / \mathrm{N}$ cells: $\beta$-catenin expression at 7,14, and 21d in culture with or without IR. Scale bars: (b) and (d) $50 \mu \mathrm{m}$, all data represented as means \pm SD. ${ }^{*} \mathrm{p}<0.05$ vs. $E ;{ }^{* \star} \mathrm{p}<0.01$ vs. $\mathrm{E} ;{ }^{\star \star \star *} \mathrm{p}<0.001$ vs. $\mathrm{E}$. 


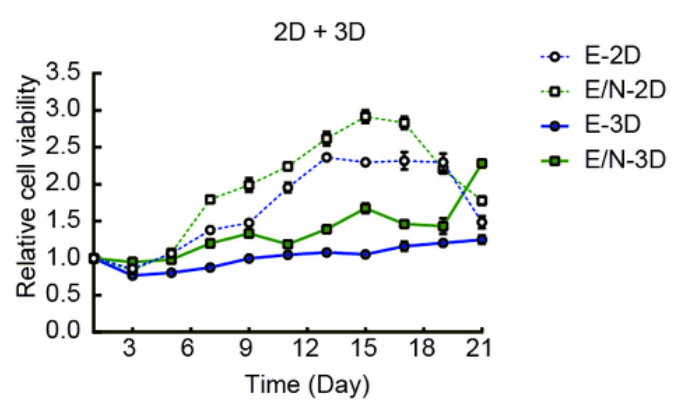

C

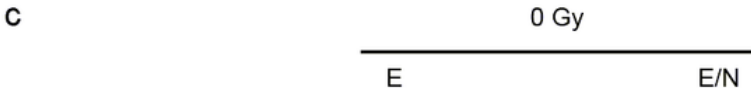

b

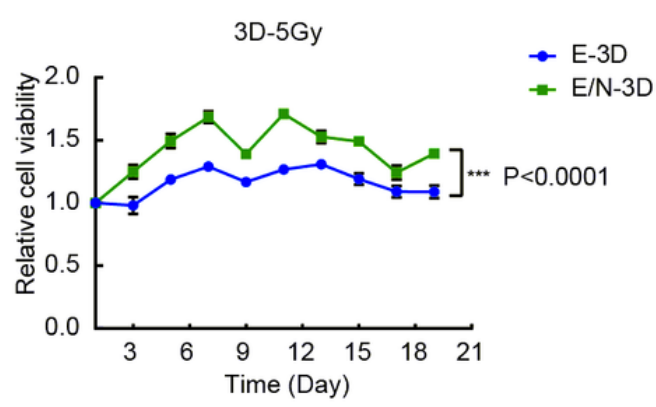

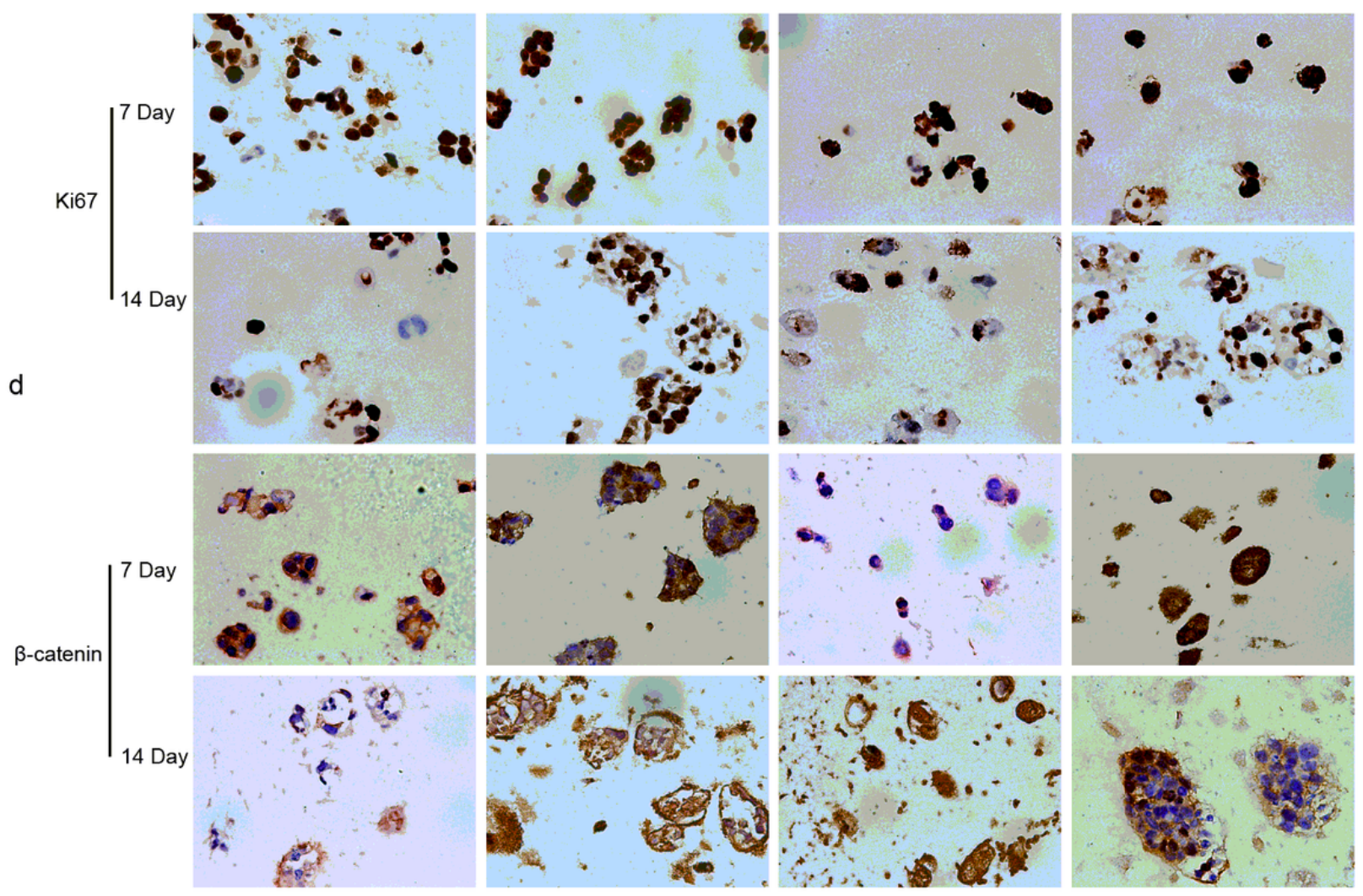

Figure 5

Overexpression of NRAGE enhanced the proliferation and radioresistance of ESCC cells in 3D bioprinted hydrogels (a) Comparing cell proliferation between $\mathrm{E}$ and $\mathrm{E} / \mathrm{N}$ in 2D and 3D by Alamar Blue assays; (b) Cell proliferation was tested by immunohistochemistry of 3D bioprinted $\mathrm{E}$ and $\mathrm{E} / \mathrm{N}$ cells: Ki-67 expression at 7,14, and 21d in culture with or without IR; (c) cell viability between $\mathrm{E}$ and $\mathrm{E} / \mathrm{N}$ in 3D after $5 \mathrm{~Gy}$ IR by Alamar Blue assays; (d) Immunohistochemistry of 3D bioprinted $\mathrm{E}$ and $\mathrm{E} / \mathrm{N}$ cells: $\beta$-catenin expression at 7,14, and 21d in culture with or without IR. Scale bars: (b) and (d) $50 \mu \mathrm{m}$, all data represented as means \pm SD. ${ }^{*} \mathrm{p}<0.05$ vs. $E ;{ }^{* \star} \mathrm{p}<0.01$ vs. $\mathrm{E} ;{ }^{\star \star \star *} \mathrm{p}<0.001$ vs. $\mathrm{E}$. 

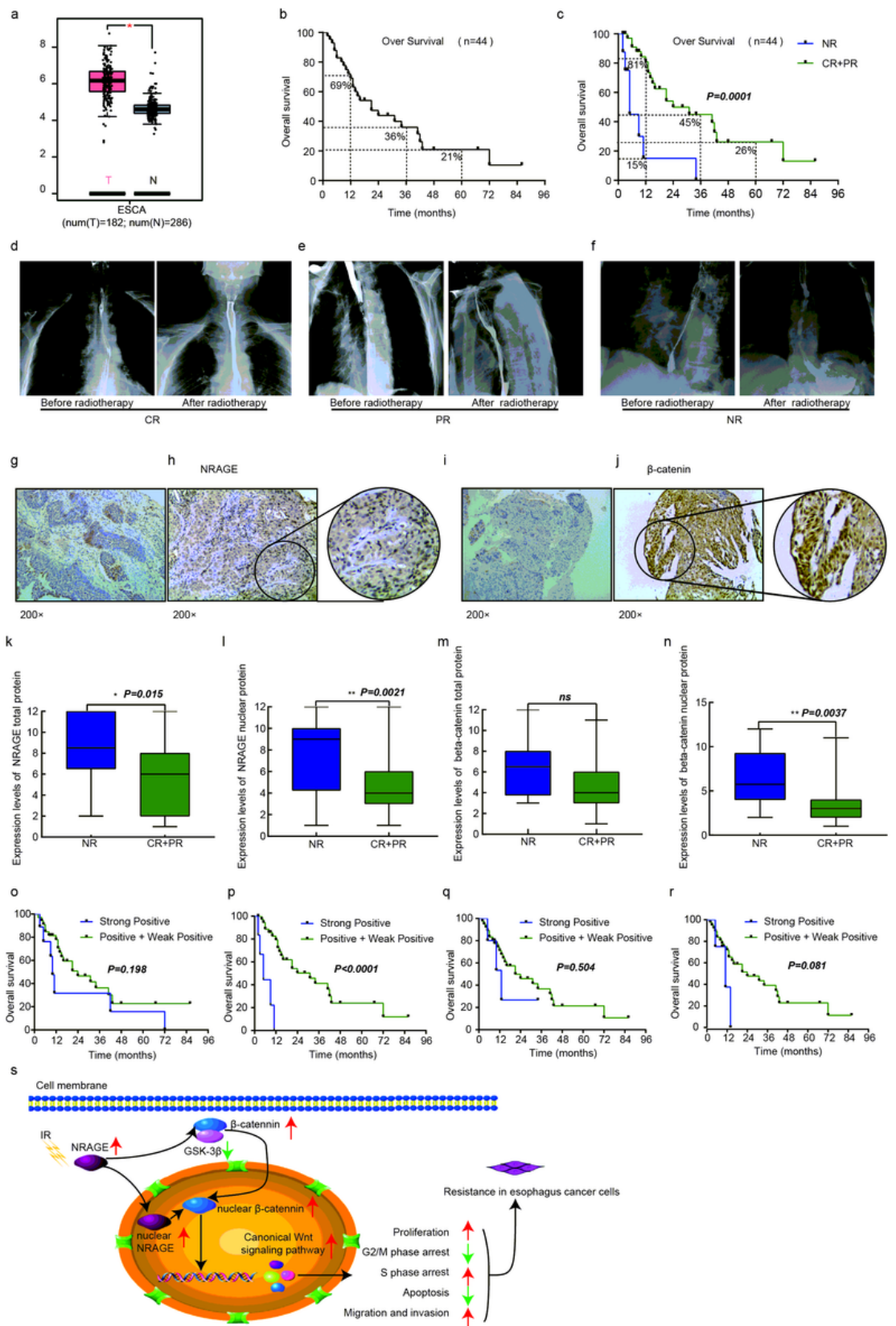

Figure 6

High expression nuclear NRAGE in patient samples with esophagus cancer following radical radiotherapy correlates with poor survival (a) NRAGE Expression in ESCC tumor tissues and normal control esophageal tissues; (b) Kaplan-Meier overall survival curves for all 44 patients with esophagus cancer; (c) Kaplan-Meier overall survival curves for all 44 patients with esophagus cancer stratified by NR and CR+PR; (d-f) Images of radiotherapeutic short-term effects, CR (d), PR (e), NR (f); (g-h)

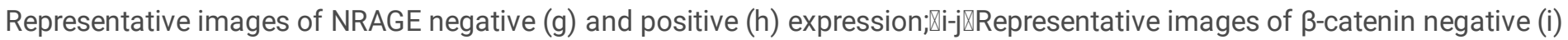
and positive (j) expression; (k-l) Comparison of NRAGE total $(k)$ and nuclear (l) protein expression between NR group and

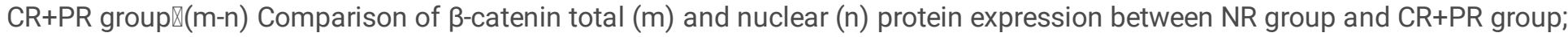
(o-p) Kaplan-Meier overall survival curves for all 44 patients with esophagus cancer stratified by strong positive and weak positive+positive expression of NRAGE total (o) and nuclear (p) protein; (q-r) Kaplan-Meier overall survival curves for all 44 patients with esophagus cancer stratified by strong positive and weak positive+positive expression of $\beta$-catenin total $(q)$ and nuclear ( $r$ ) protein; (s) Schematic illustration depicting the NRAGE associations with cancer proliferation, apoptosis, cell cycle and invasive migration that induce resistance to radiation. 

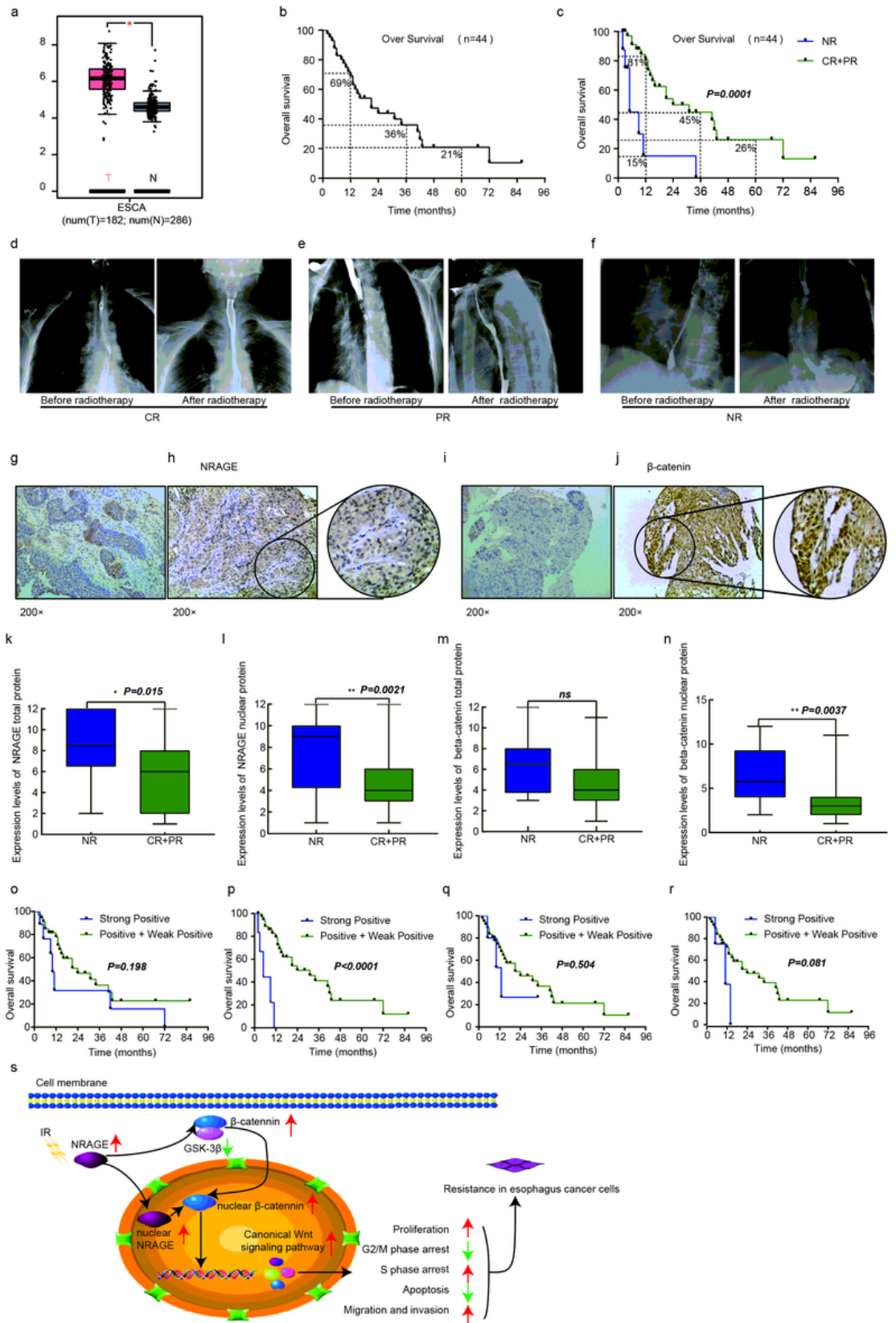

Figure 6

High expression nuclear NRAGE in patient samples with esophagus cancer following radical radiotherapy correlates with poor survival (a) NRAGE Expression in ESCC tumor tissues and normal control esophageal tissues; (b) Kaplan-Meier overall survival curves for all 44 patients with esophagus cancer; (c) Kaplan-Meier overall survival curves for all 44 patients with esophagus cancer stratified by NR and CR+PR; (d-f) Images of radiotherapeutic short-term effects, CR (d), PR (e), NR (f); (g-h)

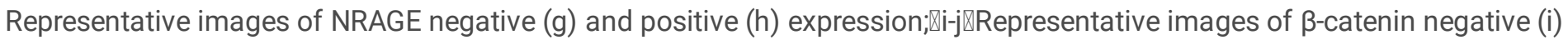
and positive (j) expression; ( $k-l)$ Comparison of NRAGE total $(k)$ and nuclear $(l)$ protein expression between NR group and

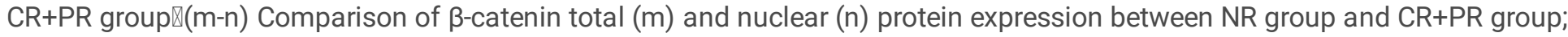
(o-p) Kaplan-Meier overall survival curves for all 44 patients with esophagus cancer stratified by strong positive and weak positive+positive expression of NRAGE total (o) and nuclear (p) protein; (q-r) Kaplan-Meier overall survival curves for all 44 patients with esophagus cancer stratified by strong positive and weak positive+positive expression of $\beta$-catenin total $(q)$ and nuclear ( $r$ ) protein; (s) Schematic illustration depicting the NRAGE associations with cancer proliferation, apoptosis, cell cycle and invasive migration that induce resistance to radiation. 

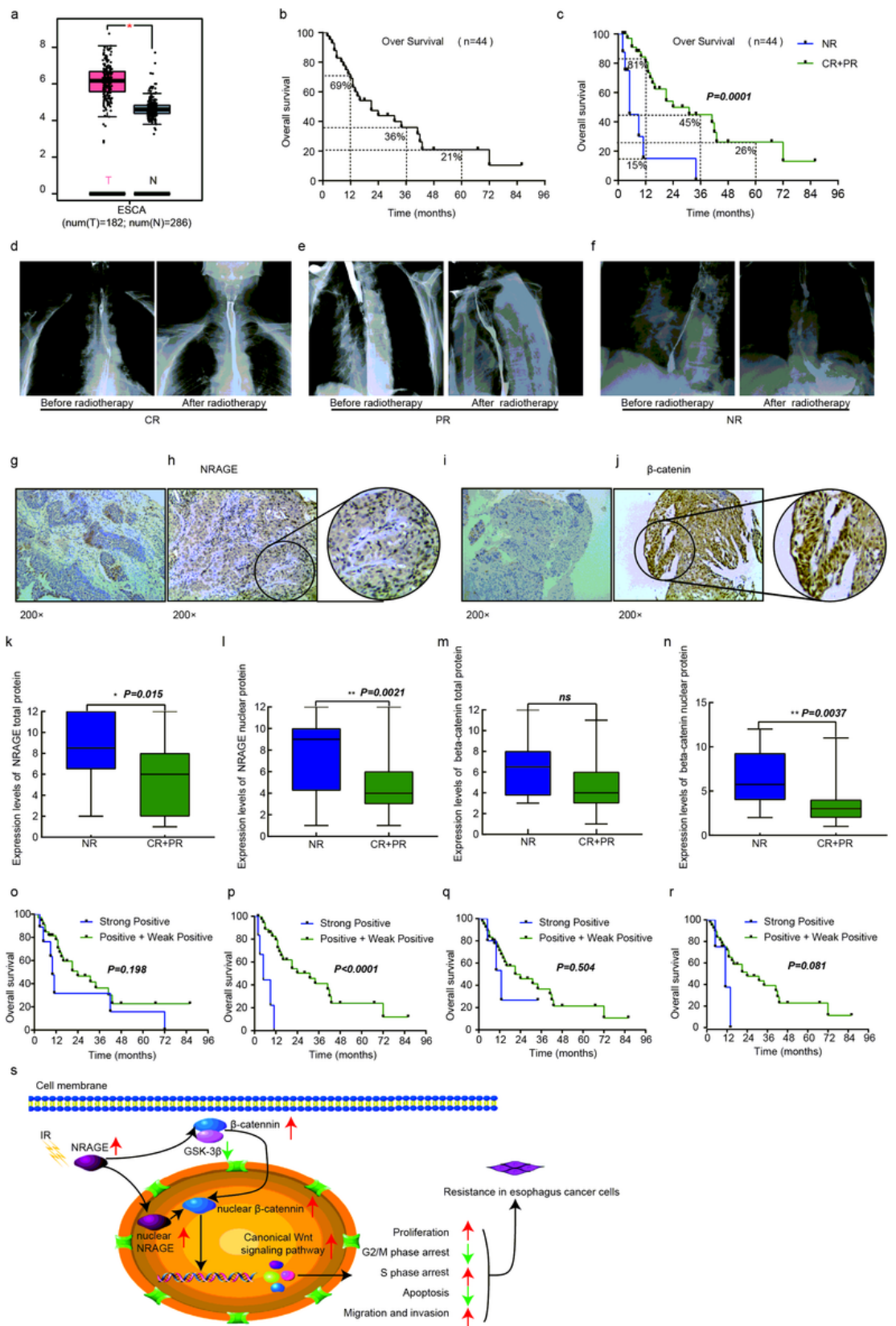

Figure 6

High expression nuclear NRAGE in patient samples with esophagus cancer following radical radiotherapy correlates with poor survival (a) NRAGE Expression in ESCC tumor tissues and normal control esophageal tissues; (b) Kaplan-Meier overall survival curves for all 44 patients with esophagus cancer; (c) Kaplan-Meier overall survival curves for all 44 patients with esophagus cancer stratified by NR and CR+PR; (d-f) Images of radiotherapeutic short-term effects, CR (d), PR (e), NR (f); (g-h)

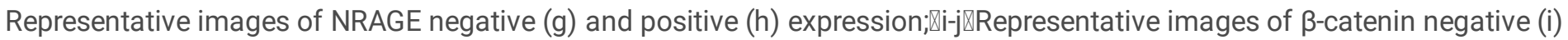
and positive (j) expression; (k-l) Comparison of NRAGE total $(k)$ and nuclear (l) protein expression between NR group and

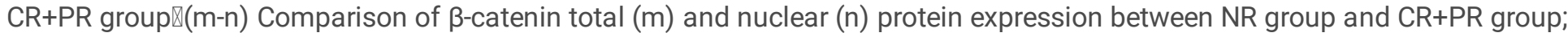
(o-p) Kaplan-Meier overall survival curves for all 44 patients with esophagus cancer stratified by strong positive and weak positive+positive expression of NRAGE total (o) and nuclear (p) protein; (q-r) Kaplan-Meier overall survival curves for all 44 patients with esophagus cancer stratified by strong positive and weak positive+positive expression of $\beta$-catenin total $(q)$ and nuclear ( $r$ ) protein; (s) Schematic illustration depicting the NRAGE associations with cancer proliferation, apoptosis, cell cycle and invasive migration that induce resistance to radiation. 


\section{Supplementary Files}

This is a list of supplementary files associated with this preprint. Click to download.

- DocumentS1.docx

- DocumentS1.docx

- DocumentS1.docx

- Stable.docx

- Stable.docx

- Stable.docx 